\title{
Quantitative Modeling of the Effects of Temperature and Inoculum Density of Fusarium oxysporum f. sp. ciceris Races 0 and 5 on Development of Fusarium Wilt in Chickpea Cultivars
}

\author{
Juan A. Navas-Cortés, Blanca B. Landa, Miguel A. Méndez-Rodríguez, and Rafael M. Jiménez-Díaz
}

First and third authors: Instituto de Agricultura Sostenible (IAS), Consejo Superior de Investigaciones Científicas (CSIC), Apartado 4084, 14080 Córdoba, Spain; and second and fourth authors: Escuela Técnica Superior de Ingenieros Agrónomos y de Montes (ETSIAM), Universidad de Córdoba (UCO), Apartado 3048, 14080 Córdoba, Spain and IAS-CSIC.

Current address of M. A. Méndez-Rodríguez: Empresa Pública de Desarrollo Agrario y Pesquero, Consejería de Agricultura y Pesca, Junta de Andalucía, 14004 Córdoba, Spain.

Accepted for publication 30 October 2006.

\begin{abstract}
Navas-Cortés, J. A., Landa, B. B., Méndez-Rodríguez, M. A., and Jiménez-Díaz, R. M. 2007. Quantitative modeling of the effects of temperature and inoculum density of Fusarium oxysporum f. sp. ciceris races 0 and 5 on development of Fusarium wilt in chickpea cultivars. Phytopathology 97:564-573.

Races 0 (Foc-0) and 5 (Foc-5) of Fusarium oxysporum f. sp. ciceris differ in virulence and induce yellowing or wilting syndrome, respectively, in chickpea. We modeled the combined effects of soil temperature and inoculum density of Foc- 0 and Foc-5 on disease developed in chickpea cvs. P-2245 and PV-61 differing in susceptibility to those races, using quantitative nonlinear models. Disease development over time in the temperature range of 10 to $30^{\circ} \mathrm{C}$ and inoculum densities between 6 and 8,000 chlamydospores $\mathrm{g}^{-1}$ of soil was described by the Weibull function. Four response variables (the reciprocal incubation period, the

disease development. Response surface models that expressed the combined effect of inoculum density and temperature were developed by substituting the intrinsic rate of disease development in the Weibull or exponential functions with a beta function describing the relationship of response variables to temperature. The models estimated 22 to $26^{\circ} \mathrm{C}$ as the most favorable soil temperature for infection of cvs. P-2245 and PV61 by Foc-5, and 24 to $28^{\circ} \mathrm{C}$ for infection of cv. P-2245 by Foc- 0 . At $10^{\circ} \mathrm{C}$, no disease developed except in cv. P-2245 inoculated with Foc-5. At optimum soil temperature, maximum disease intensity developed with Foc-5 and Foc- 0 at 6 and 50 chlamydospores $\mathrm{g}^{-1}$ of soil respectively, in cv. P-2245, and with Foc-5 at 1,000 chlamydospores $\mathrm{g}^{-1}$ of soil in cv. PV61. The models were used to construct risk threshold charts that can be used to estimate the potential risk of Fusarium wilt epidemics in a geographical area based on soil temperature, the race and inoculum density in soil, and the level of susceptibility of the chickpea cultivar.
\end{abstract} final disease intensity, the standardized area under the disease progress curve, and the intrinsic rate of disease development) characterized the
Additional keywords: Cicer arietinum.
Fusarium wilt, caused by Fusarium oxysporum Schlechtend.:Fr. f. sp. ciceris (Padwick) Matuo \& K. Sato, is the most important soilborne disease of chickpea (Cicer arietinum L.) throughout the world, particularly in the Indian subcontinent, the Mediterranean region, and California $(15,17)$. Two pathotypes exhibiting differential symptoms, namely yellowing and wilting, exist in F. oxysporum f. sp. ciceris populations (39). The yellowing pathotype induces progressive foliar yellowing with vascular discoloration, while the wilting pathotype induces rapid and severe chlorosis, flaccidity, and vascular discoloration (39). In addition to these two pathotypes, there exist eight races (race $0,1 \mathrm{~A}, 1 \mathrm{~B} / \mathrm{C}$, $2,3,4,5$, and 6 ) of $F$. oxysporum $\mathrm{f}$. sp. ciceris that can be identified based on the disease reactions of a set of differential chickpea cultivars $(14,18,20)$. Races 0 and $1 \mathrm{~B} / \mathrm{C}$ belong to the yellowing pathotype, whereas the remaining races form the wilting pathotype $(20,23,24)$. The eight races also have a distinct geographic distribution. Races 2, 3, and 4 have been reported only in India (14), whereas races $0,1 \mathrm{~B} / \mathrm{C}, 5$, and 6 are found mainly in the Mediterranean region and California $(12,18,23)$. Unlike the other races, race 1A is more widespread and has been reported in India, California, and the Mediterranean region (14,16,23). An intraspecific phylogeny of $F$. oxysporum f. sp. ciceris races in-

Corresponding author: J. A. Navas-Cortés; E-mail address: ag1nacoj@uco.es

doi:10.1094/PHYTO-97-5-0564

(c) 2007 The American Phytopathological Society ferred from DNA fingerprinting with repetitive sequences indicated that each of the eight races forms a monophyletic lineage and that they have evolved in a simple stepwise pattern, with race 0 being hypothesized as ancestor of the wilting races (22).

Studies under controlled conditions indicated that Fusarium wilt of chickpea increases with decreasing soil matric potential, and that disease can develop severely at 25 and $30^{\circ} \mathrm{C}$, but not at 15 and $20^{\circ} \mathrm{C}$, with an inoculum density of $F$. oxysporum f. sp. ciceris at 500 and 1,000 propagules $\mathrm{g}^{-1}$ of soil (3). Similarly, Sugha et al. (38) observed that an increase in inoculum density accelerated the development of chickpea wilt whereas low inoculum densities delayed the expression of wilt symptoms. However, in all of the above studies, the nature of the pathogen race was not known. In a recent study, the development of Fusarium wilt caused by race 5 was strongly affected by the incubation temperature (25). Thus, the rate of disease development was faster and final severity was higher at $25^{\circ} \mathrm{C}$ than at 20 and $30^{\circ} \mathrm{C}$, and there was a significant incubation temperature-pathogen inoculum density interaction on disease development. Although the influence of inoculum density on disease development at $25^{\circ} \mathrm{C}$ was negligible, increasing inoculum densities significantly increased final disease severity at 20 and $30^{\circ} \mathrm{C}$.

Differences in virulence among $F$. oxysporum f. sp. ciceris races bear significance in terms of disease development and management under field conditions. At equal inoculum densities, epidemics caused by race 5 develop earlier and more rapidly, and produce significantly greater yield loss, compared with those 
caused by race $0(30,32)$. However, the effectiveness of wilt management practices, such as the use of resistant cultivars, choice of sowing dates $(17,27,31)$, and biocontrol (26), is influenced by pathogen race $(14,18,26,31)$.

Quantifying the relationships and effects of pathogen, plant, and environmental factors on disease development by means of quantitative models can help in the design and efficient use of management strategies for Fusarium wilt of chickpea and other Fusarium wilt diseases. However, such a quantitative modeling approach is mostly lacking for Fusarium wilt diseases. Therefore, the objectives of this study were to quantify the combined effects of biotic (a range of virulence, inoculum density, and cultivar susceptibility) and abiotic (soil temperature) factors on development of Fusarium wilt in chickpea. The data then were analyzed to develop models to assess combinations of temperature and inoculum density under which Fusarium wilt epidemics can be predicted in certain chickpea cultivars; in addition, risk thresholds for these predictions were established. Furthermore, how the virulence of races inducing yellowing and wilting influences these relationships also was deduced from the models.

\section{MATERIALS AND METHODS}

Fungal isolates and inoculum production. Monoconidial cultures of F. oxysporum f. sp. ciceris isolates Foc 7802 (race 0, Foc-0) and Foc 8012 (race 5, Foc-5) were obtained from infected chickpea in southern Spain and are well characterized $(25,30)$. Selection of these races for the study was based on (i) their widespread distribution throughout the Mediterranean region, (ii) the large difference in virulence between them, and (iii) their belonging to different pathotypes (i.e., yellowing and wilting, for Foc-0 and Foc-5, respectively) $(25,30)$. Isolates were stored in sterile soil tubes at $4^{\circ} \mathrm{C}$. Active cultures of the isolates were obtained by placing aliquots of a soil culture onto a plate of fresh potato dextrose agar (PDA) (250 g of unpeeled potato, $20 \mathrm{~g}$ of agar, and $20 \mathrm{~g}$ of glucose liter ${ }^{-1}$ of distilled water) and incubating for 5 days at $25^{\circ} \mathrm{C}$ with a 12-h photoperiod of fluorescent and near-UV light at $36 \mu \mathrm{E} \mathrm{m}^{-2} \cdot \mathrm{s}^{-1}$.

Inoculum for the experiments consisted of chlamydospores produced in a sterile salt solution. Microconidia were produced in fresh potato dextrose broth in 250-ml flasks on an orbital shaker (Adolf Kühner AG, Birsfelden, Switzerland) adjusted at $140 \mathrm{rpm}$, and the same temperature and light conditions as PDA cultures for 7 days. Microconidia harvested by centrifugation $(6,800 \times g, 20$ $\min$ at $4^{\circ} \mathrm{C}$ ) were suspended to a final concentration of $1 \times$ $10^{7}$ microconidia $\mathrm{ml}^{-1}$ in $500 \mathrm{ml}$ of a sterile salt solution $\left(\left(\mathrm{NH}_{4}\right)_{2} \mathrm{SO}_{4}, 300 \mathrm{mg} ; \mathrm{KH}_{2} \mathrm{PO}_{4}, 120 \mathrm{mg} ; \mathrm{K}_{2} \mathrm{HPO}_{4}, 480 \mathrm{mg}\right.$; and D-glucose, $1.8 \mathrm{~g} /$ liter of distilled water) (2; J. A. Navas-Cortés, M. A. Méndez-Rodríguez, and R. M. Jiménez-Díaz, unpublished data) in $1,000-\mathrm{ml}$ flasks and incubated at $25^{\circ} \mathrm{C}$ in the dark for 4 weeks. The production of chlamydospores of $F$. oxysporum $\mathrm{f}$. sp. ciceris in the salt solution was confirmed by microscopic observations. Chlamydospores were harvested by centrifugation $\left(6,800 \times g, 20 \mathrm{~min}\right.$ at $\left.4^{\circ} \mathrm{C}\right)$, washed free of nutrients, and suspended in deionized, sterile water. Chlamydospore suspension were used to infest $25 \mathrm{~g}$ of heat-sterilized talcum powder. The infested talcum then was dried at $37^{\circ} \mathrm{C}$ for 5 to 7 days and stored at $4{ }^{\circ} \mathrm{C}$ until use. The amount of inoculum in the infested talcum powder was estimated by the number of CFU per gram of talcum. The number of CFU was determined by dilution plating on V8 juice-oxgall-pentachloronitrobenzene agar (VOPA) Fusariumselective medium $(4,25,30)$.

Chickpea plants and inoculation. 'Kabuli' (large, ram-head shaped, beige seed) chickpea cvs. P-2245 and PV-61 used in the Mediterranean region were used. Cultivar P-2245 is highly susceptible to both Foc-0 and Foc-5, whereas cv. PV-61 is moderately resistant to Foc-0 and susceptible to Foc-5 $(19,20)$. Seed were surface disinfested in $2.5 \% \mathrm{NaOCl}$ for $3 \mathrm{~min}$ and germinated on autoclaved layers of filter paper in moist chambers at $25^{\circ} \mathrm{C}$ for $48 \mathrm{~h}$. Germinated seed, selected for uniformity (length of radicle $=1$ to $2 \mathrm{~cm}$ ), were sown into $15-\mathrm{cm}$-diameter clay pots (four plants per pot) filled with an autoclaved $\left(121^{\circ} \mathrm{C}, 1 \mathrm{~h}\right.$, twice, on two consecutive days) soil mixture (clay loam/peat, 2:1, vol/vol), artificially infested with Foc-0 or Foc-5.

Effect of incubation temperature and inoculum density of $F$. oxysporum f. sp. ciceris. Plants were incubated in soil tanks (Environmental Growth Chambers; Integrated Development \& MFG/Chagrin, Fall, OH) placed inside a walk-in growth chamber adjusted to $25 \pm 1{ }^{\circ} \mathrm{C}$ and a 14-h photoperiod of fluorescent light at $360 \mu \mathrm{E} \mathrm{m}^{-2} \cdot \mathrm{s}^{-1}$ for 60 days. Pots with soil and plant roots were set inside the soil tanks at constant temperature of 10, 15, 20, 25, and $30^{\circ} \mathrm{C}$, with a maximum variation of $\pm 1^{\circ} \mathrm{C}$ for all temperatures. Plants in a pot were watered daily and fertilized with $100 \mathrm{ml}$ of a $0.1 \%, 20-5-32+$ micronutrients hydro-sol fertilizer (Haifa Chemicals, Ltd., Haifa, Israel) solution every week. Upon termination of experiments, isolations were made from stem segments of symptomless plants to determine the occurrence of vascular infections. Stem pieces of individual plants were cut into 5- to 10 -mm-long segments, surface disinfested $(0.2 \% \mathrm{NaOCl}$ for $2 \mathrm{~min}$ ), plated on VOPA, and incubated at $25^{\circ} \mathrm{C}$ and a $12-\mathrm{h}$ photoperiod for 3 to 5 days $(25,30)$.

The infested talcum powder was mixed in proportion with the autoclaved soil mixture to achieve an inoculum density of 0,24 , $50,100,200,500,1,000,2,000$, and 8,000 chlamydospores $\mathrm{g}^{-1}$ of soil for cv. P-2245-Foc-0; 0, 6, 24, 50, 100, 500, 1,000, 2,000, and 5,000 for cv. P-2245-Foc-5; and 0, 6, 24, 50, 100, 1,000, and 5,000 for cv. PV-61-Foc-5. Soil in pots that served as controls or with pathogen inoculum densities $<5,000$ (Foc-5) or 8,000 (Foc-0) chlamydospores $\mathrm{g}^{-1}$ of soil were amended with an amount of uninfested talcum powder equivalent to that of infested powder used for the highest pathogen inoculum density. The inoculum density of Foc- 0 and Foc-5 in the infested soil mixture, estimated as CFU per gram of soil, was determined just after sowing by dilution plating as previously described $(25,30)$. Estimated values of inoculum densities corresponded to those theoretically established and the number of CFU achieved for equal inoculum densities did not differ significantly among the experimental treatments. Separate experiments for each chickpea cultivar-pathogen race combination were performed using a completely randomized split-plot design, with temperature as the main plot factor and pathogen inoculum density level as the subplot factor. There were four replications (four pots with four plants each) of each treatment combination. In each separate experiment, the combination of chickpea cv. P-2245 and 1,000 chlamydospores $\mathrm{g}^{-1}$ of soil of each of $F$. oxysporum $\mathrm{f}$. sp. ciceris races 0 and 5 incubated at $25^{\circ} \mathrm{C}$ air and soil temperature also were included to test reproducibility of results across experiments. Each experiment was repeated once and preliminary analyses of variance of treatments suggested no significant differences $(P>0.05)$ among experiments. Therefore, pooled data from the experiments were analyzed.

Disease assessment and data analyses. The incidence $(0=$ plant showing no disease symptoms and $1=$ plant showing disease symptoms) and severity of symptoms were assessed at 2- to 3-day intervals. Severity was assessed on a 0-to-4 rating scale based on the percentage of foliage with yellowing or wilting in acropetal progression $(0=0 \%, 1=1$ to $33 \%, 2=34$ to $66 \%$, $3=67100 \%$, and $4=$ dead plant). Incidence and severity were used to calculate a disease intensity index (DII) for each pot $(25,30)$ using the equation DII $=\left(\Sigma S_{i} \times N_{i}\right) /\left(N_{t} \times 4\right)$; where $S_{i}$ is the symptoms severity, $N_{i}$ is the number of plants with $S_{i}$ symptoms severity, and $N_{t}$ is the total number of plants. Thus, DII expresses the mean value of disease intensity at any given moment as a proportion of the maximum possible amount of disease.

Temporal analysis. Disease progress curves (DPCs) were obtained from the accumulated DII over time in days from the 
date of sowing. The nonlinear form of the Weibull model was evaluated for goodness-of-fit to the set of DII progress data using nonlinear regression analysis. The Weibull model (equation 1) is a generalized simple model that includes both rate and shape parameters allowing it to model a wide variety of response curves (29,33). In the Weibull equation:

$$
\operatorname{DII}(t)=A_{W}\left(1-\exp \left\{-\left[B_{W}\left(t-C_{W}\right)\right]^{D_{W}}\right\}\right)
$$

where DII = disease intensity index, $A_{W}=$ upper asymptote parameter (i.e., upper limit of DII), $B_{W}=$ scale parameter (i.e., intrinsic rate of DII increase over time), $C_{W}=$ location parameter (i.e., time lag before the onset of symptom development), $D_{W}=$ shape parameter (i.e., location of inflection point), and $t=$ time of disease assessment in days after inoculation (10,33). For analyses, non-zero points for DII in experimental units and the average DII values of the replicated blocks were used.

Relationship between disease development and DPC associated variables. To further examine disease development, four additional variables associated with DPC were examined. These included (i) the incubation period (IP), established as the time in days to initial symptoms, or its reciprocal $\left(\mathrm{IP}_{\mathrm{R}}=1 / \mathrm{IP}\right)$; (ii) the final disease intensity ( $\mathrm{DII}_{\text {final }}$ ); (iii) the standardized area under the DII progress curve (SAUDPC) calculated by trapezoidal integration method standardized by duration of disease development in days $(6,27,31)$; and (iv) $B_{W}$.

Response surface models. To describe the effects of temperature (T) and inoculum density (ID) on the DPC-associated variables ( $\mathrm{IP}_{\mathrm{R}}, B_{W}, \mathrm{DII}_{\text {final }}$, and SAUDPC) for the different chickpea cultivar-pathogen race interactions, response surface models were fitted to data using nonlinear regression analysis following two steps. In the first step, two models were used to evaluate the effect of ID on DPC-associated variables. The Weibull model (equation 2) was used to represent the effect of ID on $\mathrm{IP}_{\mathrm{R}}, \mathrm{DII}_{\text {final }}$, and SAUDPC:

$$
Y_{\mathrm{ID}}=f(\mathrm{ID})=A\left(1-\exp \left\{-(r[\log (\mathrm{ID})-C])^{D}\right\}\right)
$$

where $Y$ is the response of $\mathrm{IP}_{\mathrm{R}}, \mathrm{DII}_{\text {final }}$, or SAUDPC to ID, $A$ is the upper limit of the response, $r$ is the intrinsic rate of increase in the response, $C$ is the minimum ID value for the response, and $D$ is the portion of the ID range in which the response decelerate.

Similarly, the exponential model (equation 3) was used to represent the effect of ID on $B_{W}$ :

$$
Y_{\mathrm{ID}}=f(\mathrm{ID})=E \exp [r \log (\mathrm{ID})]
$$

where $Y_{\mathrm{ID}}$ is the response of $B_{W}$ to ID, $E$ is a constant, and $r$ is the rate of the response increase.

The response of the four DPC-associated variables to $T$ was described by the modified $\beta$ function (equation 4) $(13,26)$ :

$$
\begin{gathered}
Y_{\mathrm{T}}=f(\mathrm{~T})=G\left[\left(\mathrm{~T}-T_{\min }\right) /\left(T_{\text {opt }}-T_{\min }\right)\right]^{\left[H \times(T o p t-T \min ) /\left(T_{\max }-T_{\mathrm{opt}}\right)\right]} \\
{\left[\left(T_{\max }-\mathrm{T}\right) /\left(T_{\max }-T_{\mathrm{opt}}\right)^{H}\right]}
\end{gathered}
$$

In this equation, $Y_{\mathrm{T}}$ is the response of the DPC-associated variables to temperature, and $T_{\max }$ and $T_{\min }$ were fixed to 37 and $5^{\circ} \mathrm{C}$, respectively, which are known maximum and minimum temperatures for growth of $F$. oxysporum $\mathrm{f}$. sp. ciceris isolates $(9,26)$. The shape parameter, $H$, determines the temperature range near the optimum temperature, $T_{\text {opt }}$, at which the response values are close to the maximum response $G$.

In the second step, the combined effect of ID and T on $\mathrm{IP}_{\mathrm{R}}$, DII $_{\text {final }}$, and SAUDPC were characterized by substituting $r$ in equation 2 with a description of the response to temperature (equation 5)

$$
Y_{\mathrm{T}, \mathrm{ID}}=f(\mathrm{~T}, \mathrm{ID})=A\left\{1-\exp [-f(\mathrm{~T})(\log (\mathrm{ID})-C)]^{D^{D}}\right\}
$$

in which $f(T)$ is given by equation 4 . Similarly, the combined effect of ID and T on $B_{W}$ were characterized by substituting $r$ in equation 3 with a description of the response to temperature (equation 6):

$$
Y_{\mathrm{T}, \mathrm{ID}}=f(\mathrm{~T}, \mathrm{ID})=E \exp [f(\mathrm{~T}) \log (\mathrm{ID})]
$$

in which $f(\mathrm{~T})$ is given by equation 4 .

All regression analyses were conducted using the LevenbergMarquardt's nonlinear least-squares iterative procedure of SPSS Software (version 12.0; SPSS Inc., Chicago). All derivatives were calculated numerically. The coefficient of determination $\left(R^{2}\right)$, mean square error, standard errors associated with the parameter estimates, confidence intervals of predicted values, and pattern of the standardized residuals plotted against either predicted values or the independent variable were used to evaluate the appropriateness of a model to describe the data (6).

Risk chart models. Curves derived from equations 5 and 6 for the range of temperature and inoculum density required to attain thresholds values of the disease response variables (IP, SAUDPC, and $B_{W}$ ) were used to obtain a chart for predicting risk of Fusarium wilt development for each chickpea cultivar- $F$. oxysporum f. sp. ciceris combination.

\section{RESULTS}

Treatment effects. Soil temperature, chickpea cultivar, and race and inoculum density of $F$. oxysporum f. sp. ciceris influenced the development of Fusarium wilt. Neither disease symptoms nor infection were observed in cv. PV-61 grown in soil infested with Foc-0, in spite of the broad range of inoculum densities and soil temperatures tested; similarly, no disease symptoms or infection were found at $10^{\circ} \mathrm{C}$ in $\mathrm{cv}$. PV-61 grown in soil infested with Foc-5 and cv. P-2245 grown in soil infested with Foc-0. For the remaining chickpea cultivar-pathogen race interactions, progression of DII over time varied with soil temperature and increased steadily with the increasing inoculum density (Table 1; Fig. 1). Overall, development of Fusarium wilt was optimum between 20 and $25^{\circ} \mathrm{C}$ for Foc-5 and between 25 and $30^{\circ} \mathrm{C}$ for $F o c-0$, with an interaction occurring between soil temperature and pathogen inoculum density (Table 1; Fig. 1). The increase in DII over time was adequately described by the Weibull model $\left(R^{2}>0.85\right)$ for all chickpea cultivar- $F$. oxysporum $\mathrm{f}$. sp. ciceris race-temperature-inoculum density combinations (Fig. 1).

At the optimum soil temperature indicated above and highest inoculum density, symptoms in the compatible interactions started to develop at 15 to 18 days after inoculation. At $10^{\circ} \mathrm{C}$, symptoms developed only in cv. P-2245 grown in soil infested with Foc-5 at any inoculum density, and required at least 39 days of incubation. At 15 to $30^{\circ} \mathrm{C}$ of soil temperature, the IP varied with the cultivarrace interactions and ranged from 15 to 38 days in cv. P-2245Foc-5, from 17 to 48 days in cv. P-2245-Foc-0, and from 18 to 40 days in cv. PV-61-Foc-5, with IP decreasing as the inoculum density increased. The IP for infection by Foc-5 always was smaller in cv. P-2245 than in cv. PV-61 for similar inoculum densities and incubation temperatures. The difference between the IP in these two cultivars decreased with the increase of Foc-5 inoculum density. Also, for a comparable range of inoculum densities of the two $F$. oxysporum f. sp. ciceris races, the greatest IP always occurred in cv. P-2245 grown in soil infested with the yellowing-inducing Foc-0, regardless of soil temperature (Table 1; Fig. 2).

At constant soil temperature, the time lag to symptom expression in the plants, indicated by the reciprocal of the incubation period $\left(\mathrm{IP}_{\mathrm{R}}\right)$, increased with the increase in inoculum density according to the Weibull model. At constant inoculum density, the beta function described well the $\mathrm{IP}_{\mathrm{R}}$ increase with temperature, but tended to underestimate the $\mathrm{IP}_{\mathrm{R}}$ in some combinations (Fig. 2).

The interaction between chickpea cultivar and $F$. oxysporum $\mathrm{f}$. sp. ciceris race strongly influenced Fusarium wilt severity (assessed both by DII final and SAUDPC). In the cv. P-2245-Foc-5 interaction, disease intensity reached asymptote (i.e., $\geq 0.9$ ) at all 
inoculum density-soil temperature combinations studied, except for plants incubated at $10^{\circ} \mathrm{C}\left(\mathrm{DII}_{\text {final }}\right.$ ranged from 0.3 to 0.8$)$ or at $30^{\circ} \mathrm{C}$ at the lowest inoculum density (6 chlamydospores $\mathrm{g}^{-1}$ of soil $)\left(\mathrm{DII}_{\text {final }}=0.5\right)($ Table 1$)$. When this same cv. P-2245 was inoculated with the Foc- 0 race, the values of $\mathrm{DII}_{\text {final }} \geq 0.9$ were attained at the lowest inoculum density tested (24 chlamydospores $\mathrm{g}^{-1}$ of soil) only when plants were incubated at 20,25, and

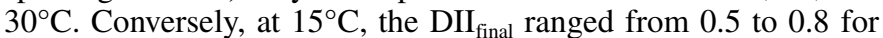
ID values $>24$ chlamydospores $\mathrm{g}^{-1}$ of soil, but no disease devel- oped in plants incubated at $10^{\circ} \mathrm{C}$ (Table 1 ; Fig. 1). In contrast, for the cv. PV-61-Foc-5 interaction, a DII final $\geq 0.9$ was attained only when inoculum density in soil was $>100$ and 1,000 chlamydospores $\mathrm{g}^{-1}$ of soil at 20 and $25^{\circ} \mathrm{C}$, respectively (Table 1; Fig. 1).

SAUDPC also was influenced by chickpea cultivar and F. oxysporum f. sp. ciceris race. At constant soil temperature, DII $_{\text {final }}$ and SAUDPC increased with the increase in inoculum density, and this increase was well described by the Weibull model (Fig. 3). Similar patterns of variation were found for both

TABLE 1. Effect of soil temperature (ST) on development of Fusarium wilt in chickpea cvs. P-2245 and PV-61 sown in soil infested with different inoculum densities (IDs) of Fusarium oxysporum f. sp. ciceris races 0 and 5

\begin{tabular}{|c|c|c|c|c|c|c|c|c|c|c|c|c|}
\hline \multirow[b]{3}{*}{$\mathrm{ST}, \mathrm{ID}^{\mathrm{b}}$} & \multicolumn{12}{|c|}{ Elements of disease progress curves ${ }^{\mathrm{a}}$} \\
\hline & \multicolumn{4}{|c|}{$\mathrm{P}-2245-F$. oxysporum f. sp. ciceris race 5} & \multicolumn{4}{|c|}{$\mathrm{P}-2245-F$. oxysporum f. sp. ciceris race 0} & \multicolumn{4}{|c|}{ PV-61-F. oxysporum f. sp. ciceris race 5} \\
\hline & $\mathrm{IP} \pm \mathrm{SE}$ & $\mathrm{DII}_{\text {final }} \pm \mathrm{SE}$ & $\mathrm{SAUDPC} \pm \mathrm{SE}$ & $B_{W} \pm \mathrm{SE}$ & $\mathrm{IP} \pm \mathrm{SE}$ & $\mathrm{DII}_{\text {final }} \pm \mathrm{SE}$ & $\mathrm{SAUDPC} \pm \mathrm{SE}$ & $B_{W} \pm \mathrm{SE}$ & $\mathrm{IP} \pm \mathrm{SE}$ & $\mathrm{DII}_{\text {final }} \pm \mathrm{SE}$ & $\mathrm{SAUDPC} \pm \mathrm{SE}$ & $B_{W} \pm \mathrm{SE}$ \\
\hline \multicolumn{13}{|l|}{10} \\
\hline 6 & $44.9 \pm 2.3$ & $0.52 \pm 0.16$ & $0.35 \pm 0.12$ & $0.018 \pm 0.001$ & na & na & na & na & $\ldots$ & $0.00 \pm 0.00$ & $0.00 \pm 0.00$ & $\ldots$ \\
\hline 24 & $51.6 \pm 2.1$ & $0.30 \pm 0.10$ & $0.16 \pm 0.03$ & $0.021 \pm 0.001$ & $\ldots$ & $0.00 \pm 0.00$ & $0.00 \pm 0.00$ & $\ldots$ & $\ldots$ & $0.00 \pm 0.00$ & $0.00 \pm 0.00$ & $\ldots$ \\
\hline 50 & $44.5 \pm 2.0$ & $0.45 \pm 0.06$ & $0.28 \pm 0.05$ & $0.024 \pm 0.001$ & $\ldots$ & $0.00 \pm 0.00$ & $0.00 \pm 0.00$ & $\ldots$ & $\ldots$ & $0.00 \pm 0.00$ & $0.00 \pm 0.00$ & $\ldots$ \\
\hline 100 & $48.9 \pm 1.6$ & $0.60 \pm 0.17$ & $0.35 \pm 0.12$ & $0.020 \pm 0.001$ & $\ldots$ & $0.00 \pm 0.00$ & $0.00 \pm 0.00$ & $\ldots$ & $\ldots$ & $0.00 \pm 0.00$ & $0.00 \pm 0.00$ & $\ldots$ \\
\hline 200 & na & na & na & na & $\ldots$ & $0.00 \pm 0.00$ & $0.00 \pm 0.00$ & $\ldots$ & na & na & na & na \\
\hline 500 & $40.8 \pm 5.8$ & $0.70 \pm 0.14$ & $0.37 \pm 0.10$ & $0.024 \pm 0.001$ & $\ldots$ & $0.00 \pm 0.00$ & $0.00 \pm 0.00$ & $\ldots$ & na & na & na & na \\
\hline 1,000 & $41.5 \pm 2.8$ & $0.72 \pm 0.12$ & $0.41 \pm 0.10$ & $0.026 \pm 0.001$ & $\ldots$ & $0.00 \pm 0.00$ & $0.00 \pm 0.00$ & $\ldots$ & $\ldots$ & $0.00 \pm 0.00$ & $0.00 \pm 0.00$ & $\ldots$ \\
\hline 2,000 & $41.7 \pm 2.3$ & $0.66 \pm 0.11$ & $0.42 \pm 0.05$ & $0.025 \pm 0.002$ & $\ldots$ & $0.00 \pm 0.00$ & $0.00 \pm 0.00$ & $\ldots$ & na & na & na & na \\
\hline 5,000 & $38.7 \pm 2.3$ & $0.84 \pm 0.06$ & $0.54 \pm 0.06$ & $0.033 \pm 0.001$ & na & na & na & na & $\ldots$ & $0.00 \pm 0.00$ & $0.00 \pm 0.00$ & $\ldots$ \\
\hline 8,000 & na & na & na & na & $\ldots$ & $0.00 \pm 0.00$ & $0.00 \pm 0.00$ & $\ldots$ & na & na & na & na \\
\hline \multicolumn{13}{|l|}{15} \\
\hline 6 & $33.1 \pm 1.2$ & $0.98 \pm 0.02$ & $0.64 \pm 0.07$ & $0.045 \pm 0.001$ & na & na & na & na & $\ldots$ & $0.00 \pm 0.00$ & $0.00 \pm 0.00$ & $\ldots$ \\
\hline 24 & $32.4 \pm 0.9$ & $1.00 \pm 0.00$ & $0.73 \pm 0.02$ & $0.054 \pm 0.001$ & $38.4 \pm 2.2$ & $0.50 \pm 0.17$ & $0.25 \pm 0.09$ & $0.020 \pm 0.001$ & $39.8 \pm 6.3$ & $0.20 \pm 0.09$ & $0.11 \pm 0.03$ & $0.008 \pm 0.001$ \\
\hline 50 & $32.6 \pm 0.9$ & $1.00 \pm 0.00$ & $0.70 \pm 0.01$ & $0.053 \pm 0.001$ & $46.0 \pm 1.1$ & $0.47 \pm 0.12$ & $0.27 \pm 0.05$ & $0.021 \pm 0.001$ & $40.0 \pm 4.7$ & $0.20 \pm 0.20$ & $0.09 \pm 0.09$ & $0.013 \pm 0.001$ \\
\hline 100 & $36.1 \pm 1.4$ & $0.98 \pm 0.02$ & $0.70 \pm 0.06$ & $0.047 \pm 0.001$ & $42.8 \pm 2.4$ & $0.52 \pm 0.14$ & $0.34 \pm 0.22$ & $0.019 \pm 0.001$ & $38.8 \pm 3.1$ & $0.27 \pm 0.24$ & $0.17 \pm 0.15$ & $0.039 \pm 0.001$ \\
\hline 200 & na & na & na & na & $45.1 \pm 1.4$ & $0.65 \pm 0.03$ & $0.37 \pm 0.08$ & $0.032 \pm 0.001$ & na & na & na & na \\
\hline 500 & $34.1 \pm 1.3$ & $0.99 \pm 0.01$ & $0.69 \pm 0.06$ & $0.044 \pm 0.001$ & $47.5 \pm 2.2$ & $0.69 \pm 0.12$ & $0.37 \pm 0.15$ & $0.019 \pm 0.001$ & na & na & na & na \\
\hline 1,000 & $34.1 \pm 0.8$ & $0.99 \pm 0.01$ & $0.78 \pm 0.02$ & $0.064 \pm 0.011$ & $37.4 \pm 1.4$ & $0.78 \pm 0.05$ & $0.43 \pm 0.02$ & $0.031 \pm 0.001$ & $36.0 \pm 2.9$ & $0.29 \pm 0.13$ & $0.16 \pm 0.06$ & $0.031 \pm 0.001$ \\
\hline 2,000 & $33.0 \pm 0.9$ & $1.00 \pm 0.00$ & $0.78 \pm 0.02$ & $0.060 \pm 0.001$ & $37.4 \pm 2.5$ & $0.84 \pm 0.13$ & $0.50 \pm 0.21$ & $0.023 \pm 0.001$ & na & na & na & na \\
\hline 5,000 & $34.2 \pm 1.1$ & $1.00 \pm 0.00$ & $0.73 \pm 0.02$ & $0.067 \pm 0.002$ & na & na & na & na & $26.5 \pm 4.6$ & $0.41 \pm 0.24$ & $0.25 \pm 0.15$ & $0.029 \pm 0.002$ \\
\hline 8,000 & na & na & na & na & $39.8 \pm 2.3$ & $0.76 \pm 0.12$ & $0.45 \pm 0.22$ & $0.054 \pm 0.011$ & na & na & na & na \\
\hline \multicolumn{13}{|l|}{20} \\
\hline 6 & $21.3 \pm 0.8$ & $1.00 \pm 0.00$ & $0.85 \pm 0.03$ & $0.050 \pm 0.002$ & na & na & na & na & $\ldots$ & $0.00 \pm 0.00$ & $0.00 \pm 0.00$ & $\cdots$ \\
\hline 24 & $17.4 \pm 0.4$ & $1.00 \pm 0.00$ & $0.90 \pm 0.01$ & $0.082 \pm 0.001$ & $30.3 \pm 1.6$ & $0.99 \pm 0.00$ & $64 \pm 0.05$ & $0.043 \pm 0.006$ & $23.2 \pm 2.9$ & $0.34 \pm 0.03$ & $0.23 \pm 0.04$ & $0.024 \pm 0.001$ \\
\hline 50 & $17.4 \pm 0.6$ & $1.00 \pm 0.00$ & $0.89 \pm 0.01$ & $0.080 \pm 0.004$ & $27.4 \pm 0.9$ & $1.00 \pm 0.00$ & $0.82 \pm 0.03$ & $0.064 \pm 0.001$ & $25.5 \pm 2.2$ & $0.88 \pm 0.06$ & $0.55 \pm 0.07$ & $0.033 \pm 0.001$ \\
\hline 100 & $17.5 \pm 0.6$ & $1.00 \pm 0.00$ & $0.89 \pm 0.01$ & $0.095 \pm 0.034$ & $27.8 \pm 1.0$ & $1.00 \pm 0.00$ & $0.76 \pm 0$ & $0.054 \pm 0.001$ & $22.9 \pm 1.4$ & $0.91 \pm 0.04$ & $0.55 \pm 0.06$ & $0.043 \pm 0.001$ \\
\hline 200 & na & na & na & na & $23.6 \pm 0.9$ & $1.00 \pm 0.00$ & $0.84 \pm 0.02$ & $0.040 \pm 0.001$ & na & na & na & na \\
\hline 500 & $15.4 \pm 0.4$ & $1.00 \pm 0.00$ & $0.91 \pm 0.01$ & $0.130 \pm 0.001$ & $24.5 \pm 1.0$ & $1.00 \pm 0.00$ & $0.84 \pm 0.01$ & $0.074 \pm 0.001$ & na & na & na & na \\
\hline 1,000 & $16.1 \pm 0.6$ & $1.00 \pm 0.00$ & $0.88 \pm 0.02$ & $0.151 \pm 0.001$ & $24.5 \pm 0.8$ & $1.00 \pm 0.00$ & $0.85 \pm 0.03$ & $0.075 \pm 0.001$ & $20.3 \pm 1.5$ & $1.00 \pm 0.00$ & $0.75 \pm 0.01$ & $0.072 \pm 0.001$ \\
\hline 2,000 & $16.4 \pm 0.4$ & $1.00 \pm 0.00$ & $0.91 \pm 0.01$ & $0.172 \pm 0.002$ & $22.9 \pm 0.5$ & $1.00 \pm 0.00$ & $0.88 \pm 0.03$ & $0.086 \pm 0.002$ & na & na & na & na \\
\hline 5,000 & $15.1 \pm 0.4$ & $1.00 \pm 0.00$ & $0.90 \pm 0.02$ & $0.175 \pm 0.001$ & na & na & na & na & $18.4 \pm 0.3$ & $1.00 \pm 0.00$ & $0.92 \pm 0.02$ & $0.082 \pm 0.003$ \\
\hline 8,000 & na & na & na & na & $21.9 \pm 1.0$ & $1.00 \pm 0.00$ & $0.80 \pm 0.02$ & $0.085 \pm 0.001$ & na & na & na & na \\
\hline \multicolumn{13}{|l|}{25} \\
\hline 6 & $19.1 \pm 0.7$ & $1.00 \pm 0.00$ & $36 \pm 0.01$ & $0.064 \pm 0.011$ & na & na & na & na & $29.5 \pm 1.0$ & $0.15 \pm 0.09$ & $13 \pm 0$ & $0.030 \pm 0.001$ \\
\hline 24 & $19.3 \pm 1.1$ & $1.00 \pm 0.00$ & $0.88 \pm 0.02$ & $0.103 \pm 0.001$ & $31.1 \pm 1.2$ & $0.98 \pm 0.02$ & $0.64 \pm 0.05$ & $0.041 \pm 0.001$ & $25.3 \pm 1.3$ & $0.83 \pm 0.09$ & $0.57 \pm 0.11$ & $0.051 \pm 0.015$ \\
\hline 50 & $16.6 \pm 0.5$ & $1.00 \pm 0.00$ & $0.93 \pm 0.01$ & $0.166 \pm 0.004$ & $25.9 \pm 1.9$ & $1.00 \pm 0.00$ & $0.81 \pm 0.08$ & $0.075 \pm 0.001$ & $21.4 \pm 1.1$ & $0.83 \pm 0.10$ & $0.63 \pm 0.06$ & $0.062 \pm 0.020$ \\
\hline 100 & $19.4 \pm 1.2$ & $1.00 \pm 0.00$ & $0.86 \pm 0.04$ & $0.105 \pm 0.030$ & $26.1 \pm 0.7$ & $1.00 \pm 0.00$ & $0.80 \pm 0.03$ & $0.062 \pm 0.015$ & $19.4 \pm 0.9$ & $0.84 \pm 0.09$ & $0.68 \pm 0.11$ & $0.093 \pm 0.003$ \\
\hline 200 & na & na & na & na & $20.6 \pm 0.6$ & $1.00 \pm 0.00$ & $0.90 \pm 0.02$ & $0.098 \pm 0.013$ & na & na & na & na \\
\hline 500 & $15.3 \pm 0.4$ & $1.00 \pm 0.00$ & $0.93 \pm 0.01$ & $0.134 \pm 0.021$ & $23.1 \pm 1.0$ & $1.00 \pm 0.00$ & $0.83 \pm 0.03$ & $0.083 \pm 0.001$ & na & na & na & na \\
\hline 1,000 & $16.6 \pm 0.6$ & $1.00 \pm 0.00$ & $0.93 \pm 0.01$ & $0.142 \pm 0.010$ & $21.1 \pm 0.7$ & $1.00 \pm 0.00$ & $0.89 \pm 0.03$ & $0.118 \pm 0.043$ & $21.5 \pm 0.6$ & $1.00 \pm 0.00$ & $0.84 \pm 0.04$ & $0.079 \pm 0.029$ \\
\hline 2,000 & $15.0 \pm 0.3$ & $1.00 \pm 0.00$ & $0.94 \pm 0.01$ & $0.248 \pm 0.068$ & $18.3 \pm 0.4$ & $1.00 \pm 0.00$ & $0.91 \pm 0.01$ & $0.140 \pm 0.023$ & na & na & na & na \\
\hline 5,000 & $18.3 \pm 1.3$ & $1.00 \pm 0.00$ & $0.91 \pm 0.03$ & $0.273 \pm 0.001$ & na & na & na & na & $18.9 \pm 0.3$ & $1.00 \pm 0.00$ & $0.92 \pm 0.01$ & $0.131 \pm 0.005$ \\
\hline 8,000 & na & na & na & na & $16.6 \pm 0.4$ & $1.00 \pm 0.00$ & $0.91 \pm 0.02$ & $0.160 \pm 0.004$ & na & na & na & na \\
\hline \multicolumn{13}{|l|}{30} \\
\hline 6 & $37.8 \pm 4.2$ & $0.49 \pm 0.16$ & $0.25 \pm 0.09$ & $0.016 \pm 0.001$ & na & na & na & na & $31.5 \pm 4.6$ & $0.09 \pm 0.06$ & $0.07 \pm 0.04$ & $0.029 \pm 0.001$ \\
\hline 24 & $27.0 \pm 3.3$ & $0.96 \pm 0.04$ & $0.60 \pm 0.11$ & $0.044 \pm 0.004$ & $24.5 \pm 1.3$ & $1.00 \pm 0.00$ & $0.76 \pm 0.10$ & $0.074 \pm 0.001$ & $32.3 \pm 4.8$ & $0.20 \pm 0.09$ & $0.12 \pm 0.04$ & $0.023 \pm 0.001$ \\
\hline 50 & $17.5 \pm 1.1$ & $1.00 \pm 0.00$ & $0.85 \pm 0.05$ & $0.100 \pm 0.011$ & $23.4 \pm 1.2$ & $0.94 \pm 0.06$ & $0.78 \pm 0.05$ & $0.069 \pm 0.008$ & $22.8 \pm 4.3$ & $0.16 \pm 0.06$ & $0.13 \pm 0.05$ & $0.033 \pm 0.001$ \\
\hline 100 & $20.3 \pm 1.7$ & $1.00 \pm 0.00$ & $0.76 \pm 0.06$ & $0.063 \pm 0.001$ & $21.8 \pm 1.0$ & $1.00 \pm 0.00$ & $0.83 \pm 0.03$ & $0.078 \pm 0.001$ & $21.6 \pm 2.1$ & $0.09 \pm 0.06$ & $0.07 \pm 0.05$ & $0.038 \pm 0.003$ \\
\hline 200 & na & na & na & na & $17.3 \pm 0.6$ & $1.00 \pm 0.00$ & $0.88 \pm 0.02$ & $0.077 \pm 0.010$ & na & na & na & na \\
\hline 500 & $15.1 \pm 0.4$ & $1.00 \pm 0.00$ & $0.90 \pm 0.02$ & $0.170 \pm 0.006$ & $22.6 \pm 2.2$ & $0.98 \pm 0.02$ & $0.73 \pm 0.12$ & $0.075 \pm 0.002$ & na & na & na & na \\
\hline 1,000 & $15.9 \pm 0.4$ & $1.00 \pm 0.00$ & $0.91 \pm 0.02$ & $0.200 \pm 0.001$ & $18.5 \pm 0.7$ & $1.00 \pm 0.00$ & $0.89 \pm 0.01$ & $0.100 \pm 0.001$ & $20.2 \pm 2.1$ & $0.37 \pm 0.08$ & $0.26 \pm 0.06$ & $0.039 \pm 0.001$ \\
\hline 2,000 & $15.1 \pm 0.4$ & $1.00 \pm 0.00$ & $0.95 \pm 0.01$ & $0.220 \pm 0.003$ & $18.1 \pm 0.6$ & $1.00 \pm 0.00$ & $0.92 \pm 0.01$ & $0.104 \pm 0.001$ & na & na & na & na \\
\hline 5,000 & $15.0 \pm 0.3$ & $1.00 \pm 0.00$ & $0.92 \pm 0.01$ & $0.231 \pm 0.002$ & na & na & na & na & $17.8 \pm 0.6$ & $0.48 \pm 0.12$ & $0.37 \pm 0.08$ & $0.045 \pm 0.001$ \\
\hline 8,000 & na & na & na & na & $16.8 \pm 1.0$ & $1.00 \pm 0.00$ & $0.88 \pm 0.01$ & $0.130 \pm 0.002$ & na & na & na & na \\
\hline
\end{tabular}

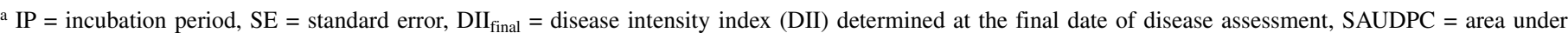
disease intensity progress curve estimated by the trapezoidal integration method standardized by duration time in days, $B_{W}=$ estimated values of the intrinsic rate parameter of the Weibull model adjusted to DII progress over time, na $=$ not assayed, and $\ldots=$ no disease developed.

b ID measured in chlamydospores $\mathrm{g}^{-1}$ of soil. 
DII $_{\text {final }}$ and SAUDPC; therefore, only the analysis for SAUDPC is shown and described below (Fig. 3). SAUDPC increased steadily in the cv. PV-61-Foc-5 interaction with the increase in the inoculum density at all soil temperatures for which disease developed. In contrast, in cv. P-2245 infected with either Foc-5 or Foc-0, such relationships were observed only for the lower and higher temperatures assayed at which disease developed. For the remaining soil temperatures in the study, the maximum values of SAUDPC were attained with an inoculum density as low as 50 chlamydospores $\mathrm{g}^{-1}$ of soil, and higher levels of inoculum made SAUDPC increase asymptotically (Fig. 3). For a given soil temperature, major differences in SAUDPC across levels of inoculum density were due to chickpea cultivar. In cv. P-2245, differences in SAUDPC due to F. oxysporum f. sp. ciceris races decreased as soil temperature approached the optimum. Thus, the mean SAUDPC across all the inoculum densities tested in plants infected with $F o c-0$ was $50 \%$ lower than that in plants infected with $F o c-5$ at $15^{\circ} \mathrm{C}$, but that difference decreased to only $10 \%$ at 20 and $25^{\circ} \mathrm{C}$, and the values for the two races were nearly identical at $30^{\circ} \mathrm{C}$ (Table 1). Similarly, according to SAUDPC values, cv. P-2245 showed a highly susceptible reaction to Foc-5, and this susceptibility was greater than that shown by cv. PV-61 to the same race. However, that difference in susceptibility to Foc-5 between these two chickpea cultivars was strongly influenced by soil temperature. Thus, compared with cv. PV-61, the mean SAUDPC attained in cv. P-2245 across inoculum densities was 78

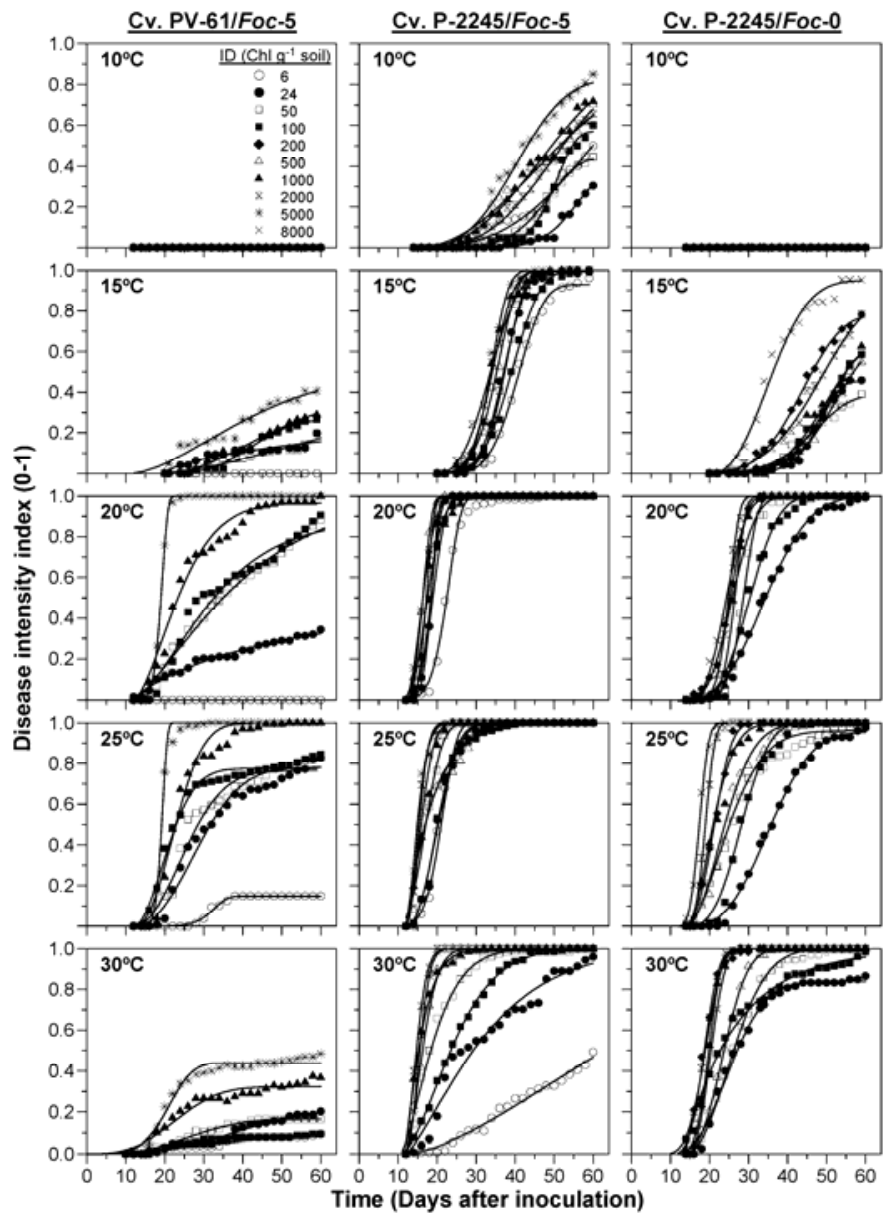

Fig. 1. Fusarium wilt disease progress in chickpea cvs. P-2245 and PV-61 grown in soil infested with different inoculum densities (IDs) (6 to 8,000 chlamydospores $\mathrm{g}^{-1}$ soil) of Fusarium oxysporum f. sp. ciceris races 0 and 5 and incubated at $10,15,20,25$, and $30^{\circ} \mathrm{C}$. Each point is the mean disease intensity index calculated with data from two repeated experiments, each comprising four pots and four plants per pot at 2- to 3-day intervals. Solid lines represent the predicted disease progress curve calculated by the Weibull function. and $76 \%$ higher at the extreme temperatures of 15 and $30^{\circ} \mathrm{C}$, respectively, and 33 and $19 \%$ higher at 20 and $25^{\circ} \mathrm{C}$, respectively (Table 1).

At each level of inoculum density, the effect of soil temperature on SAUDPC was well described by the beta function (equation 4). The estimates of the shape parameter $H$ decreased with the increase in the level of inoculum density, indicating that a wide range of temperature exists for which the SAUDPC remains near to a maximum value (Table 1). Overall, for a given inoculum density, the $H$ parameter was highest for the cv. PV-61-Foc-5 interaction, resulting in narrow optimum curves, compared with that estimated for the cv. P-2245-Foc-5 and cv. P-2245-Foc-0 interactions (Table 1; Fig. 3).

The intrinsic rate of DII increase $\left(B_{W}\right)$ also was influenced by both the incubation temperature and the pathogen inoculum density. In general, for each inoculum density-incubation temperature combination, $B_{W}$ increased for $\mathrm{cv}$. PV-61-Foc-5, cv. $\mathrm{P}-2245-F o c-0$, and cv. P-2245-Foc-5, in that order; that is, according to the increasing degree of compatibility in the plantpathogen interaction. For all the experimental combinations, $B_{W}$ increased with the increase in pathogen inoculum density according to an exponential model (Table 1; Fig. 4). Differences between $B_{W}$ for low and high inoculum densities and all chickpea cultivar-pathogen race combinations were highest at incubation temperatures $>15^{\circ} \mathrm{C}$ (Fig. 4), with the highest values of the exponential model rate parameter ( $r$ in equation 3 ) being attained at

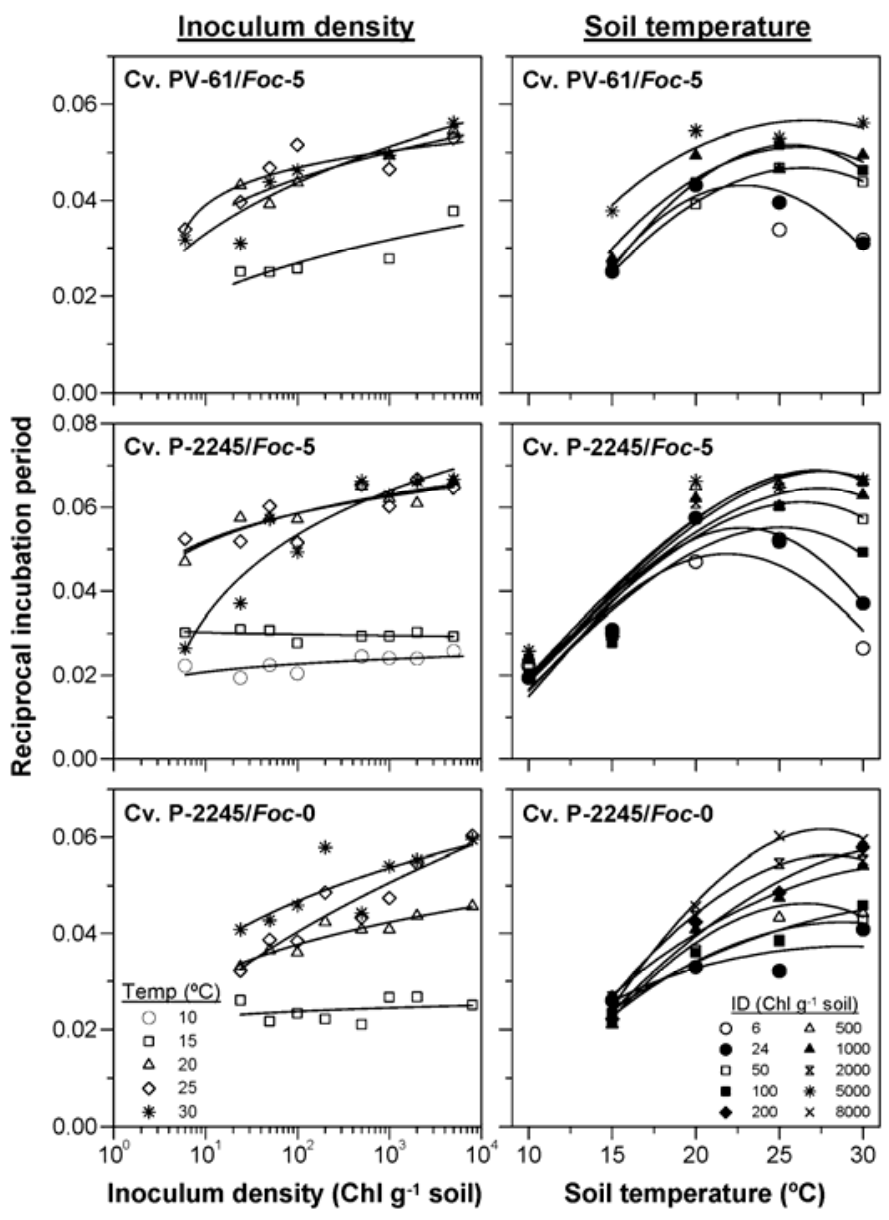

Fig. 2. Relationship between reciprocal of the incubation period (time to initial symptoms) of Fusarium wilt in chickpea cvs. PV-61 and P-2245 and the inoculum density of Fusarium oxysporum f. sp. ciceris races 0 (Foc-0) and 5 (Foc-5) (left panels) or soil temperature (right panels). Each point is the mean of data from two repeated experiments, each comprising four pots and four plants per pot. Solid line represents the predicted function calculated by the Weibull equation for inoculum density, or the beta equation for soil temperature. 
20,25 , and $30^{\circ} \mathrm{C}$. On the other hand, at constant inoculum density, $B_{W}$ increased with temperature to an optimum $\left(>20^{\circ} \mathrm{C}\right)$ and then decreased at the highest temperature tested, $30^{\circ} \mathrm{C}$, this pattern of variation being well described by the beta function (Fig. 4).

Response surfaces describing the effect of inoculum density and temperature on Fusarium wilt development. The response surfaces fitted to $\mathrm{IP}_{\mathrm{R}}, \mathrm{SAUDPC}$, and $B_{W}$ data are shown in Figure 5. The response surface for the combined effects of soil temperature and inoculum density on $\mathrm{IP}_{\mathrm{R}}$ indicated that $27^{\circ} \mathrm{C}$ was the optimum soil temperature for symptom expression in cv. P-2245 by Foc-0. This optimum temperature was significantly higher $(P$ $<0.05$ ) than $25^{\circ} \mathrm{C}$, predicted as optimum for plants infected with Foc-5 (Table 2). In the response surface, the $A$ (upper limit) parameter estimate increased and the $H$ (shape) estimate decreased for cv. PV-61-Foc-5, cv. P-2245-Foc-5, and cv. P2245-Foc-0 interactions, in that order (Table 2; Fig. 5). This indicated that the maximum $\mathrm{IP}_{\mathrm{R}}$ (i.e., shorter IP) increased and the range of temperatures near the optimum was broader for a maximum response as virulence of the Foc-race or susceptibility of chickpea cultivar in the interaction increased (Table 2; Fig. 5). At the optimum soil temperature, the IP was shortest, with Foc-5 density of at least 100 and 1,000 chlamydospores $\mathrm{g}^{-1}$ of soil in cvs. P-2245 and PV-61, respectively; or with Foc-0 at $>2,000$ chlamydospores $\mathrm{g}^{-1}$ of soil in cv. P-2245 (Fig. 5).

The response surface for the combined effects of soil temperature and inoculum density on SAUDPC estimated that $26^{\circ} \mathrm{C}$

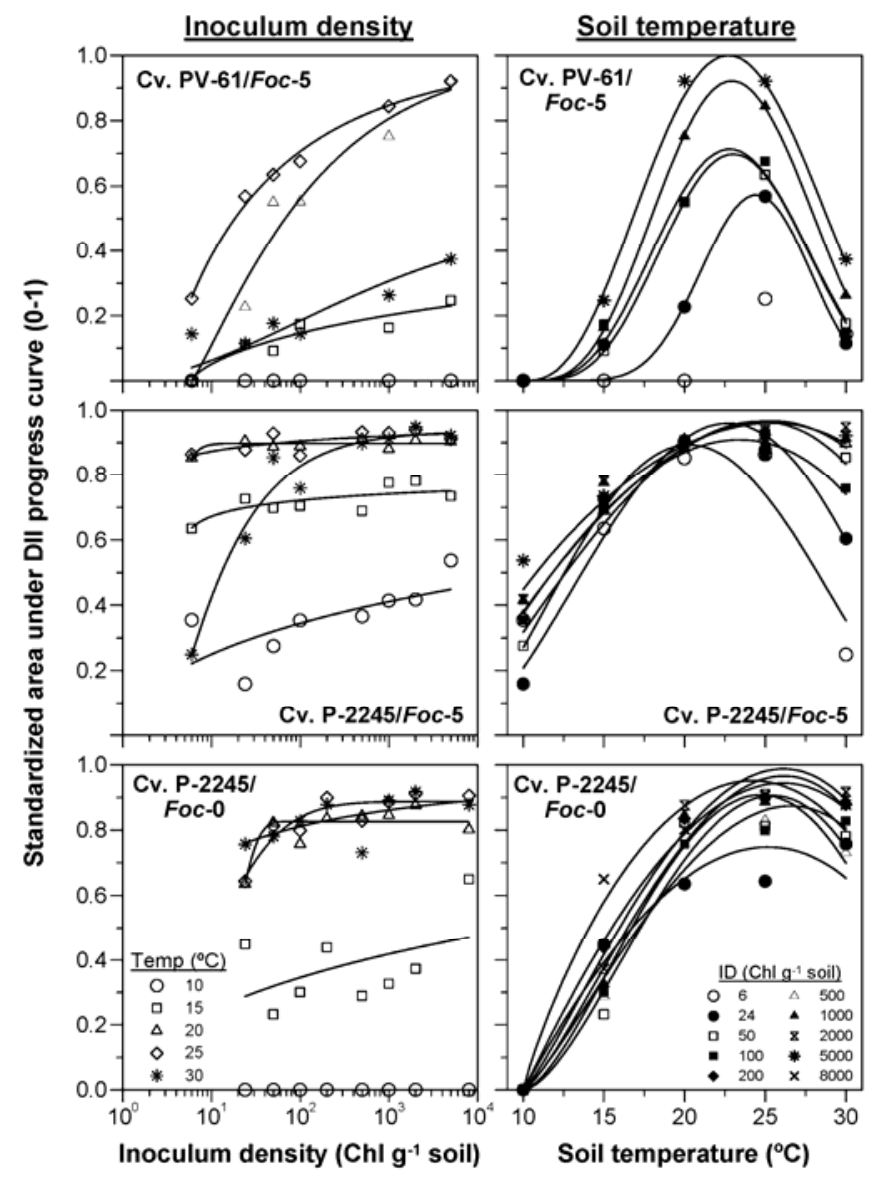

Fig. 3. Relationship between the standardized area under the disease intensity index progress curve of Fusarium wilt in chickpea cvs. PV-61 and P-2245 and the inoculum density of Fusarium oxysporum f. sp. ciceris races 0 (Foc-0) and 5 (Foc-5) (left panels) or soil temperature (right panels). Each point is the mean of data from two repeated experiments, each comprising four pots and four plants per pot. Solid line represents the predicted function calculated by the Weibull equation for inoculum density, or the beta equation for soil temperature. was an optimum temperature for maximum SAUDPC in the cv. P2245-Foc-0 interaction, but such a temperature was significantly $(P<0.05)$ lower in cvs. P-2245 $\left(24^{\circ} \mathrm{C}\right)$ and PV-61 $\left(23^{\circ} \mathrm{C}\right)$ infected by Foc-5 (Table 2, Fig. 5). The highest value (7.1) of the shape parameter, $H$, was estimated for the cv. PV-61-Foc-5 interaction compared with that in cv. P-2245 infected with either Foc-0 or Foc-5, for which the $H$ parameter was estimated at 2.7 and 1.9, respectively. This indicates that, for the cv. PV-61-Foc-5 interaction, there was a narrower range of temperatures near the optimum for a maximum disease response in the plant to the pathogen. Thus, SAUDPC values for cv. P-2245 infected by the two races were nearly constant over a broad temperature range around the optimum temperature (Table 2; Fig. 5). At the optimum soil temperature, maximum SAUDPC values in cv. P-2245 developed with an inoculum density of Foc-5 at $\geq 100$ chlamydospores $\mathrm{g}^{-1}$ of soil and Foc-0 at 1,000 chlamydospores $\mathrm{g}^{-1}$ of soil. However, for the moderately susceptible cv. PV-61, maximum SAUDPC values were obtained only with an inoculum density of Foc-5 of $>1,500$ chlamydospores $\mathrm{g}^{-1}$ of soil (Fig. 5).

In the response surface of $B_{W}$ to the combined effects of soil temperature and inoculum density, the optimum temperature (24 to $25^{\circ} \mathrm{C}$ ) for maximum rate of disease development $\left(B_{W}\right)$ was similar $(P \geq 0.05)$ in cvs. P-2245 and PV-61 infected with the highly virulent Foc-5; however, the maximum rate for disease development in cv. P-2245 infected with the less virulent Foc-0 occurred at a significantly $(P<0.05)$ higher optimum temperature $\left(27^{\circ} \mathrm{C}\right)$ (Table 2 ; Fig. 5). Also, a significantly higher $(P<0.05)$

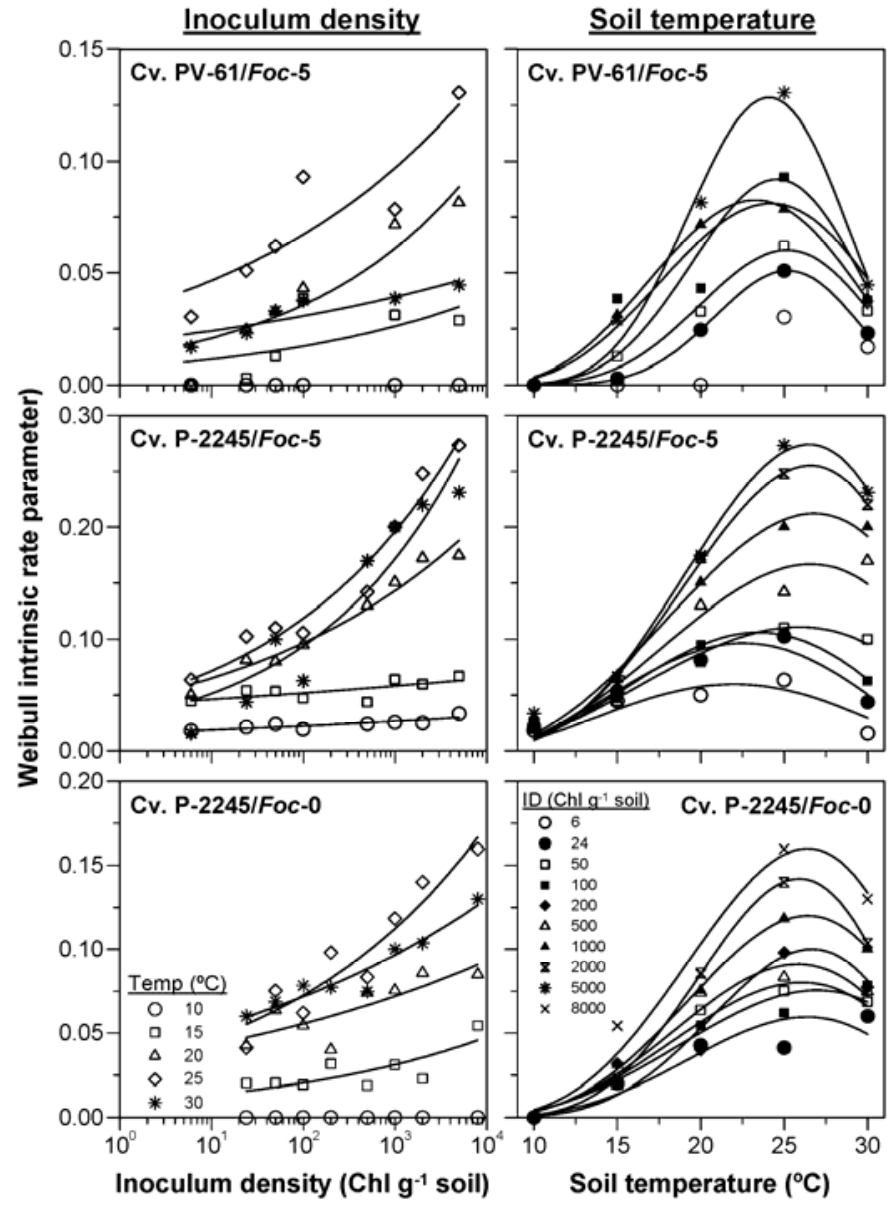

Fig. 4. Relationship between the Weibull intrinsic rate of Fusarium wilt increase parameter in chickpea cvs. PV-61 and P-2245 and inoculum density of Fusarium oxysporum f. sp. ciceris races 0 (Foc-0) and 5 (Foc-5) (left panels) or soil temperature (right panels). Each point is the mean of data from two repeated experiments, each comprising four pots and four plants per pot. Solid line represents the predicted function calculated by the Weibull equation for inoculum density, or the beta equation for soil temperature. 
value of the $H$ shape parameter was obtained for the cv. PV-61Foc-5 interaction compared with the estimated values in cv. P2245 infected with either Foc-0 or Foc-5. This indicates that $B_{W}$ varies in a narrow temperature range around the optimum temperature for disease development in cv. PV-61 plants infected with Foc-5 (Table 2; Fig. 5). At the optimum soil temperature, the highest $B_{W}$ values in cv. P-2245 occurred with Foc-0 at $\geq 1,000$ chlamydospores $\mathrm{g}^{-1}$ of soil; however, Foc-5 densities of only 25 and 500 chlamydospores $\mathrm{g}^{-1}$ of soil were needed to obtain maximum $B_{W}$ values for cvs. P-2245 and PV-61, respectively (Fig. 5).

Risk threshold models. Risk threshold models indicated that severe Fusarium wilt in the moderately susceptible cv. PV-61 would occur only when soil temperature was within the range of 20 to $30^{\circ} \mathrm{C}$ and inoculum density at least 1,500 chlamydospores $\mathrm{g}^{-1}$ of soil for the highly virulent Foc-5. In contrast, development of a similar amount of disease in the highly susceptible cv. P2245 required Foc-5 at only 50 chlamydospores $\mathrm{g}^{-1}$ of soil, or 500 chlamydospores $\mathrm{g}^{-1}$ of soil for the less virulent Foc-0. Under conditions of 20 to $30^{\circ} \mathrm{C}$ and 500 chlamydospores $\mathrm{g}^{-1}$ of soil in the most compatible cv. P-2245-Foc-5 interaction, symptoms were predicted to appear 17 days after inoculation, disease severity to attain a SAUDPC value $>0.9$, and epidemics to develop at a $B_{W}$ rate $>0.12$ DII per day, achieving maximum SAUDPC values 25 days after inoculation (Fig. 6).

Similarly, low disease was predicted to develop in highly susceptible cv. P-2245 when soil temperature was $<12^{\circ} \mathrm{C}$ or $>30^{\circ} \mathrm{C}$ and inoculum density of Foc-0 or Foc-5 was $<2$ chlamydospores $\mathrm{g}^{-1}$ of soil and, for the less susceptible cv. PV-61, when Foc-5 was $<10$ chlamydospores $\mathrm{g}^{-1}$ of soil. Within these soil temperature and inoculum density ranges, symptoms of Fusarium wilt are predicted to take at least 45 days to develop and further disease is predicted to proceed at a $B_{W}$ rate $>0.03$ DII per day, to eventually reach a maximum SAUDPC value $>0.05$ by 60 days after inoculation (Fig. 6). Finally, if soil temperature is $<10^{\circ} \mathrm{C}$, no disease is predicted to occur in cv. PV-61 grown in soil infested with Foc-5 or Foc-0, and in cv. P-2245 grown in soil infested with Foc-0, even at an inoculum density of Foc-5 or Foc-0 at 5,000 or 8,000 chlamydospores $\mathrm{g}^{-1}$ of soil, respectively.

\section{DISCUSSION}

In this study, under controlled conditions, the combined effects of virulence and inoculum density of the race, susceptibility of the cultivar, and soil temperature on development of Fusarium wilt in chickpea caused by $F$. oxysporum f. sp. ciceris were described and quantified for the first time using nonlinear models. Results illustrated the complexity of soil temperature-race virulencecultivar susceptibility interactions in the response of chickpea cultivars to $F$. oxysporum f. sp. ciceris races. In our study, the most favorable soil temperatures for development of Fusarium wilt over a range of 6 to 8,000 chlamydospores $\mathrm{g}^{-1}$ of soil were between 20 and $25^{\circ} \mathrm{C}$ for infection of cvs. P 2245 and PV-61 by

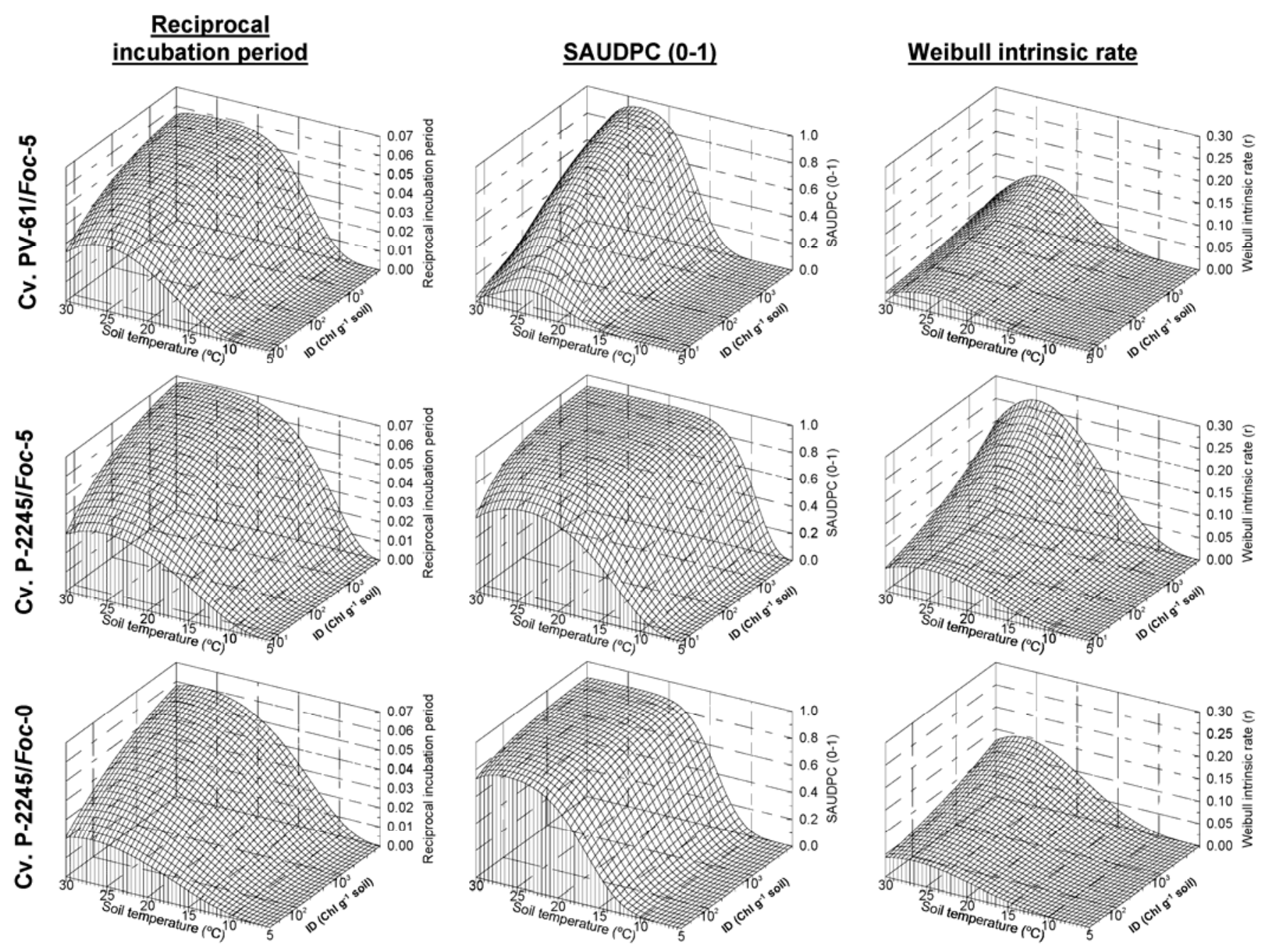

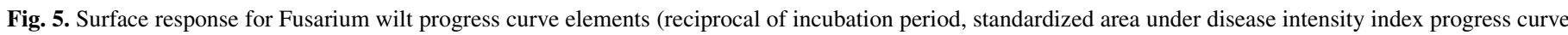

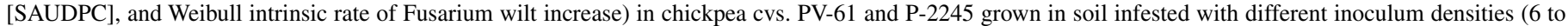

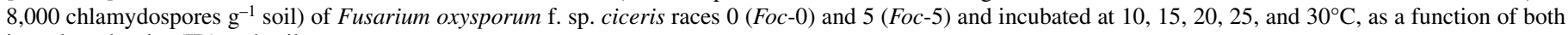
inoculum density (ID) and soil temperature. 
Foc-5, and between 20 and $30^{\circ} \mathrm{C}$ for infection of cv. P-2245 by Foc-0, which is consistent with previous studies in the growth chamber $(25,30)$ and in field $(7,11,27,31,32)$.

Sparse information was available about temperatures that limit infection or disease development by Fusarium wilt pathogens. Compared with previous studies, our results differ mainly in the cardinal temperatures for disease development. Indeed, unlike some previous reports $(3,7,11)$ of disease developing at $10^{\circ} \mathrm{C}$, no disease developed at this temperature in our study, except for the cv. P2245-Foc-5 interaction, for which symptoms occurred over the entire range of soil temperature $\left(10\right.$ to $\left.30^{\circ} \mathrm{C}\right)$ and inoculum density assayed (6 to 5,000 chlamydospores $\mathrm{g}^{-1}$ of soil). Moreover, in our study, infection by the pathogen was not impaired at $30^{\circ} \mathrm{C}$ for race 0 , the less virulent of $F$. oxysporum $\mathrm{f}$. sp. ciceris races, as reported previously $(20,23,30)$. Temperatures $>30^{\circ} \mathrm{C}$ were reported to reduce infection and Fusarium wilt development in chickpea $(3,36)$. Differences in virulence of the pathogen races, or in susceptibility of the chickpea cultivars, may account for the discrepancy in the temperature optima for Fusarium wilt development. It is remarkable that optimum temperature for mycelial growth and conidia production of different $F$. oxysporum $\mathrm{f}$. sp. ciceris races also is optimum for infection $(8,9,26)$. Furthermore, it is worth noting that, in races 0 and 5 used in this study, both maximum mycelial growth and maximum disease intensity occurred at a temperature significantly higher for Foc-0 compared with that for Foc-5 (9).

The effect of soil temperature on Fusarium wilt development in chickpea has important implications in the development and use of resistant cultivars as well as in race pathotyping of $F$. oxysporum f. sp. ciceris isolates (28). Joint studies in Israel and Spain showed that cvs. Ayala and PV-1 were moderately resistant and resistant, respectively, to $F$. oxysporum $\mathrm{f}$. sp. ciceris race $1 \mathrm{~A}$ at $24^{\circ} \mathrm{C}$ but highly susceptible at $27^{\circ} \mathrm{C}$. A similar but less pronounced effect occurred for cv. Ayala infected with $F$. oxysporum f. sp. ciceris race 6 (28). In our study, susceptible reaction of chickpea cultivars to $F$. oxysporum $\mathrm{f}$. sp. ciceris races 0 and 5 was modified only in chickpea cv. P-2245 at $10^{\circ} \mathrm{C}$, for which symptoms developed in plants infected by the highly virulent Foc-5 only. The other chickpea cultivar-Foc race interactions in the study were conducive to disease at all of the inoculum densities assayed; however, soil temperature had a strong influence on the rate of development and final disease severity.

Increasing understanding of the effect of soil temperature on development of Fusarium wilt in chickpea also has significance regarding cropping practices that may be used to manage this disease. Recent field studies in Israel indicated that the high resistant reaction of cv. Ayala to Fusarium wilt expressed when sown in mid- to late January was shifted to a moderately susceptible reaction under warmer temperatures when the sowing was delayed to late February or early March (28). Conversely, in southern Spain, advancing the sowing date from early spring to early winter delayed epidemic onset, reduced the rate of Fusarium wilt development, reduced the final amount of disease, and increase chickpea seed yield $(27,31,32)$. The optimum temperature range of 20 to $30^{\circ} \mathrm{C}$ found in this study is close to temperatures prevalent in southern Spain in spring, when chickpea traditionally is grown and Fusarium wilt develops more severely $(27,31,32,39)$.

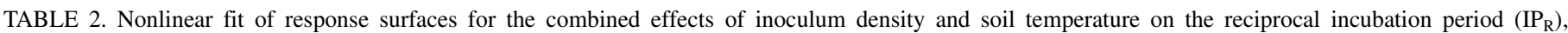

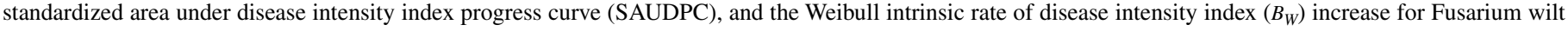

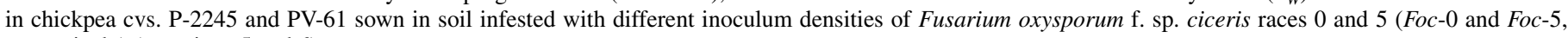
respectively) (equations 5 and 6)

\begin{tabular}{|c|c|c|c|c|c|c|c|c|c|c|}
\hline \multirow{2}{*}{$\begin{array}{l}\text { Elements, } \\
\text { cultivar/race }\end{array}$} & \multicolumn{7}{|c|}{ Parameter estimates $^{\mathrm{a}}$} & \multicolumn{3}{|c|}{ Statistics $^{b}$} \\
\hline & $A \pm \mathrm{SE}$ & $C \pm \mathrm{SE}$ & $D \pm \mathrm{SE}$ & $E \pm \mathrm{SE}$ & $G \pm \mathrm{SE}$ & $T_{\text {opt }} \pm \mathrm{SE}$ & $H \pm \mathrm{SE}$ & MSE & $R^{2}$ & Res. \\
\hline \multicolumn{11}{|l|}{$\overline{\mathrm{IP}_{\mathrm{R}}}$} \\
\hline \multirow[t]{2}{*}{ PV-61/Foc -5} & 0.0600 & 0.0001 & 11.8968 & $\ldots$ & 0.0890 & 25.1414 & 2.4854 & 0.000029 & 0.779 & $\mathrm{R}$ \\
\hline & 0.0035 & $<0.0001$ & 1.1397 & $\ldots$ & 0.0085 & $<0.0001$ & $\overline{0.3449}$ & & & \\
\hline \multirow[t]{2}{*}{$\mathrm{P}-2245 / F o c-5$} & $\underline{0.0720}$ & $0.0024^{*}$ & $10.6335^{*}$ & $\ldots$ & $0.0805^{*}$ & 25.2000 & 1.4244 & 0.000115 & 0.669 & $\mathrm{R}$ \\
\hline & $<\overline{0.0001}$ & $<0.0001$ & 0.6386 & $\ldots$ & 0.0048 & $<0.0001$ & 0.2198 & & & \\
\hline \multirow[t]{2}{*}{$\mathrm{P}-2245 / F o c-0$} & 0.0722 & 0.0000 & 8.5795 & $\ldots$ & 0.0565 & $26.7992 *$ & 1.2290 & 0.000034 & 0.792 & $\mathrm{R}$ \\
\hline & 0.0102 & 0.0000 & 0.7575 & $\ldots$ & 0.0113 & 0.0050 & 0.1840 & & & \\
\hline \multicolumn{11}{|l|}{ SAUDPC } \\
\hline \multirow[t]{2}{*}{ PV-61/Foc-5 } & $\underline{0.9995}$ & $\underline{0.5583}$ & 0.8845 & $\ldots$ & $\underline{0.9997}$ & 23.3822 & 7.1116 & 0.003915 & 0.965 & $\mathrm{R}$ \\
\hline & 0.0062 & 0.0644 & 0.0849 & $\ldots$ & 0.0029 & 0.1742 & $\overline{0.4960}$ & & & \\
\hline \multirow[t]{2}{*}{ P-2245/Foc-5 } & $0.9221 *$ & $0.1660^{*}$ & $18.4123^{*}$ & $\ldots$ & 0.1197 & 24.0173 & 1.9288 & 0.011097 & 0.860 & $\mathrm{R}$ \\
\hline & 0.0297 & 0.0348 & 1.5119 & $\ldots$ & 0.0098 & 1.1694 & 0.5308 & & & \\
\hline \multirow[t]{2}{*}{$\mathrm{P}-2245 / F o c-0$} & 0.8868 & 0.0000 & 5.3190 & $\ldots$ & $0.3203^{*}$ & $26.1321 *$ & $2.6874 *$ & 0.005400 & 0.961 & $\mathrm{R}$ \\
\hline & 0.0007 & 0.0000 & 0.2664 & $\ldots$ & 0.0161 & 0.1040 & 0.0130 & & & \\
\hline \multicolumn{11}{|l|}{$B_{W}$} \\
\hline \multirow[t]{2}{*}{ PV-61/Foc -5} & $\ldots$ & $\ldots$ & $\ldots$ & 0.3983 & 0.0284 & 24.2560 & $\underline{3.8018}$ & 0.000141 & 0.882 & $\mathrm{R}$ \\
\hline & $\ldots$ & $\ldots$ & $\ldots$ & 0.0264 & 0.0021 & 0.1765 & $\overline{0.3945}$ & & & \\
\hline \multirow[t]{2}{*}{$\mathrm{P}-2245 / F o c-5$} & $\ldots$ & $\ldots$ & $\ldots$ & $\underline{0.4555}^{*}$ & $\underline{0.0497^{*}}$ & 24.8000 & 1.7595 & 0.000798 & 0.856 & $\mathrm{R}$ \\
\hline & $\ldots$ & $\ldots$ & $\ldots$ & $<\overline{0.0001}$ & $\overline{0.0024}$ & 0.4618 & 0.3089 & & & \\
\hline \multirow[t]{2}{*}{$\mathrm{P}-2245 /$ Foc -0} & $\ldots$ & $\ldots$ & $\ldots$ & 0.3568 & 0.0391 & $26.5002 *$ & 1.6812 & 0.000095 & 0.952 & $\mathrm{R}$ \\
\hline & $\ldots$ & $\ldots$ & $\ldots$ & 0.0065 & $<0.0001$ & 0.0178 & 0.0032 & & & \\
\hline
\end{tabular}

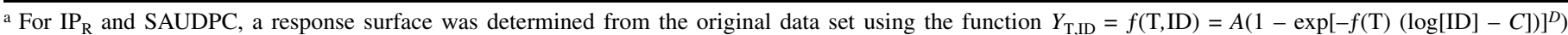
(equation 5), in which $A$ is the upper limit of the response, $r$ is the intrinsic rate of increase in the response, $C$ is the length of delay in the response, and $D$ is the portion of the period of inoculum density (ID) in which the response decelerate. Similarly, for $B_{W}$, a response surface was determined using the function $Y_{\mathrm{T}, \mathrm{ID}}=$ $f(\mathrm{~T}, \mathrm{ID})=E \exp (f[\mathrm{~T}] \log [\mathrm{ID}])$ (equation 6), in which $E$ is a constant. In both equations, the intrinsic rate of increase is expressed as a function of temperature given by $Y_{\mathrm{T}}=f(\mathrm{~T})=G\left(\left[\mathrm{~T}-T_{\min }\right] /\left[T_{\text {opt }}-T_{\min }\right]\right)^{(H \times[T \text { opt-Tmin }] /[T \max -T \text { opt }])}\left(\left[T_{\max }-\mathrm{T}\right] /\left[T_{\max }-T_{\text {opt }}\right]^{H}\right)$ (equation 4$)$. In this equation, $Y_{\mathrm{T}}$ is the response of the disease progress curve element to temperature, $T_{\max }$ and $T_{\min }$ were fixed to 37 and $5^{\circ} \mathrm{C}$, respectively $(9,26)$. The shape parameter, $H$, determines the temperature range near the optimum temperature, $T_{\mathrm{opt}}$, at which the response values are close to the maximum response $G$. SE $=$ standard error.

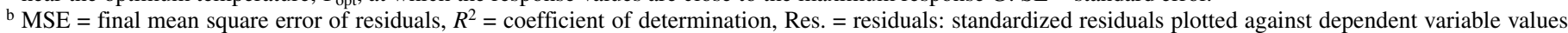
observed or predicted from nonlinear regression analysis. Patterns of residuals with a random scatter (R), after visual inspection of residual plots. For each parameter estimate, underlined parameter value in a column is significantly higher $(P<0.05)$ than the corresponding value at the other chickpea cultivar. A parameter value followed by an asterisk indicates the parameter value for a pathogen race in a column is significantly higher $(P<0.05)$ than the corresponding parameter value at the other pathogen race.

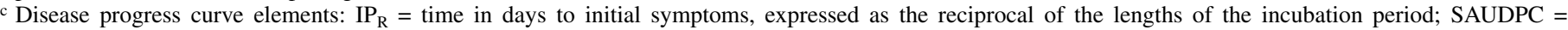
estimated by the trapezoidal integration method standardized by duration time in days; and $B_{W}=$ intrinsic rate of DII increase obtained by the estimates of parameters of the Weibull model fitted to DII progress data. 
The effects of inoculum density and soil temperature on Fusarium wilt development followed Liebig's Law of the Minimum $(1,5)$. Thus, at extreme temperatures, plants were either asymptomatic or developed moderate disease even when inoculum density was optimum for disease development. Similarly, at low inoculum density, no or little disease developed even at soil temperatures optimal for F. oxysporum f. sp. ciceris infection. In contrast, when conditions led to development of disease, limitations in a deficient factor were compensated by another factor, according to the compensation phenomenon as defined by Rotem $(1,34)$. In our study, disease in moderately compatible cultivar-race interactions developed when soil temperature was favorable even though inoculum density was marginal.
The development of risk threshold charts may have application in predicting the potential threat for development of Fusarium wilt epidemics at levels of inoculum density and temperatures under field conditions prevalent in the Mediterranean region. The model can be used to identify locations and soils of high risk for Fusarium wilt development. Based on our results, it is predicted that severe Fusarium wilt will develop at 20 to $30^{\circ} \mathrm{C}$ and an inoculum density of $F$. oxysporum $\mathrm{f}$. sp. ciceris races 5 and 0 of at least 6 and 100 chlamydospores $\mathrm{g}^{-1}$ of soil, respectively. The efficient application of the risk models will require the identification of the races of $F$. oxysporum f. sp. ciceris that prevail in a geographical area as well as the level of resistance of local or commercial cultivars. Polymerase chain reaction-based techniques currently
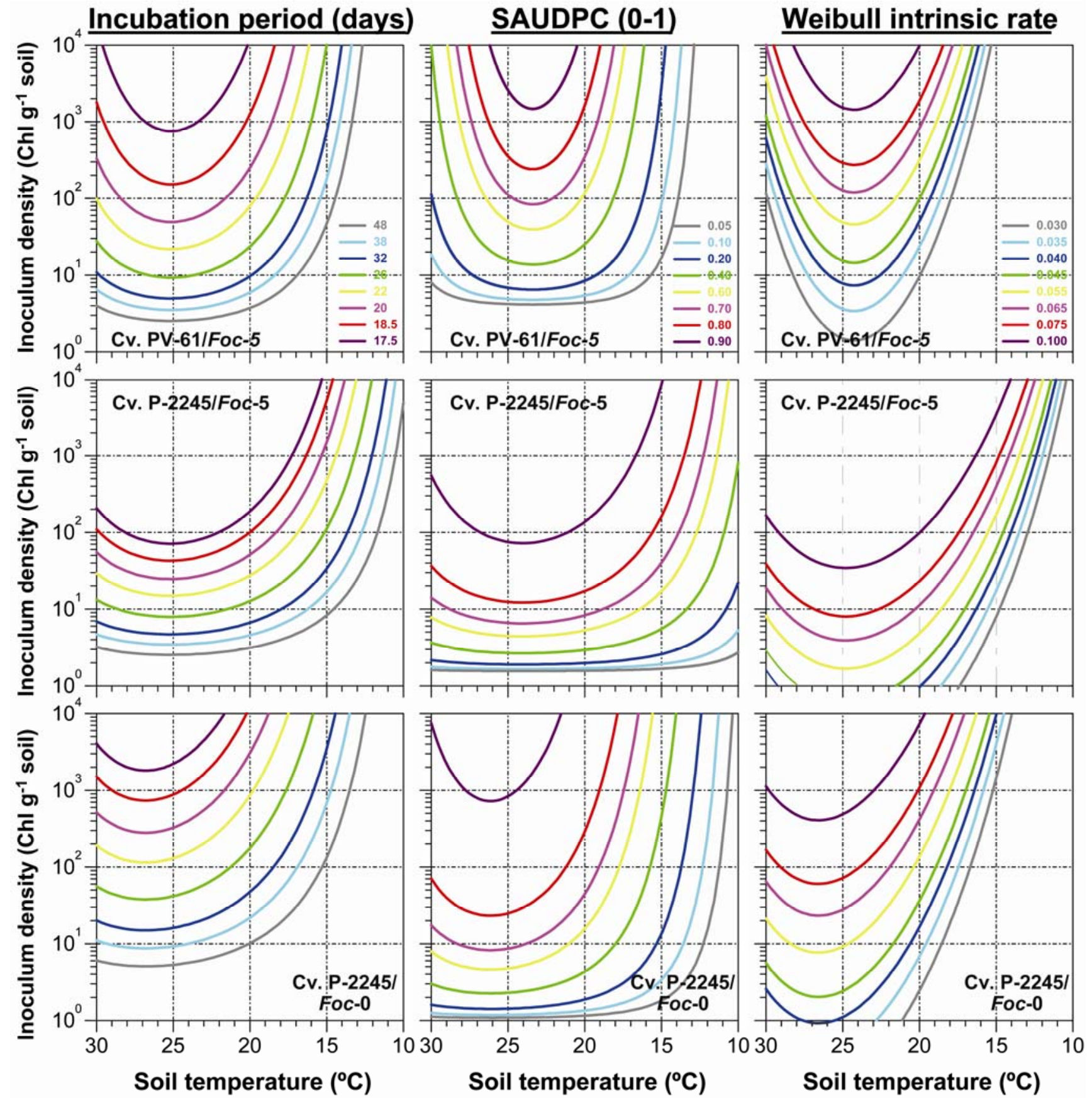

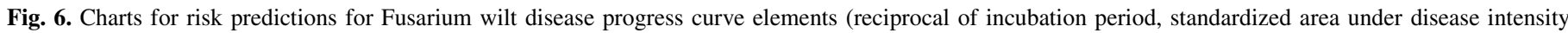

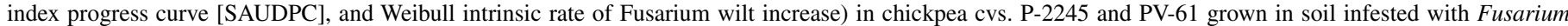

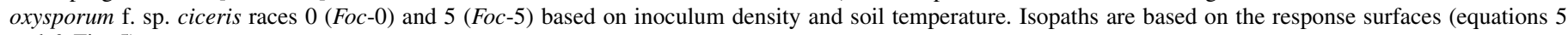
and 6, Fig. 5). 
are available for the rapid identification of $F$. oxysporum f. sp. ciceris races prevailing in a soil, and cultivars resistant to some of the most extensively spread races have been developed $(21,23$, $24,35,37)$, thus making practical the implementation of the risk model developed in this study.

\section{ACKNOWLEDGMENTS}

This work was supported by grants AGF97-1479 and AGL 200401231/AGR from Comisión Interministerial de Ciencia y Tecnología of Spain, HA 1997-0033 from Ministerio de Educación y Cultura, and Fundación Alonso Martín Escudero of Spain. B. B. Landa is a contract holder of the Ramón y Cajal program from Ministerio de Educación y Ciencia of Spain. We thank P. Castillo, W. E. Fry, T. C. Paulitz, and K. V. Subbarao for critically reading the manuscript prior to submission; and the senior editor and reviewers for their helpful comments and suggestions.

\section{LITERATURE CITED}

1. Aust, H. J., Bashi, E., and Rotem, J. 1980. Flexibility of plant pathogens in exploiting ecological and biotic conditions in the development of epidemics. Pages 46-56 in: Comparative Epidemiology. J. Palti and J. Kranz, eds. Pudoc, Wageningen, The Netherlands.

2. Barran, L. R., Schneider, E. F., and Seaman, W. L. 1977. Requirements for the rapid conversion of macroconidia of Fusarium sulphureum to chlamydospores. Can. J. Microbiol. 23:148-151.

3. Bhatti, M. A., and Kraft, J. M. 1992. Effects of inoculum density and temperature on root rot and wilt of chickpea. Plant Dis. 76:50-54.

4. Bouhot, D., and Rouxel, F. 1971. Technique sélective et quantitative d'analyse des Fusarium oxysporum et Fusarium solani dans le sol. Mode d'emploi. Ann. Phytopathol. 3:251-254.

5. Browne, C. A. 1942. Leibig and the Law of the Minimum. In: Leibig and After Leibig. F. R. Moulton, ed. Publ. Am. Assoc. Adv. Sci. 16:71-82.

6. Campbell, C. L., and Madden, L. V. 1990. Introduction to Plant Disease Epidemiology. John Wiley \& Sons, New York.

7. Chauhan, S. K. 1963. Influence of different soil temperatures on the incidence of Fusarium wilt of gram (Cicer arietinum L.). Proc. Nat. Acad. Sci. India B33:552-554.

8. Desai, S., Nene, Y. L., and Reddy, A. G. R. 1994. Races of Fusarium oxysporum causing wilt in chickpea: Growth variability. Indian J. Mycol. Plant Pathol. 24:120-127.

9. Duro-Almazán, M. D. 2000. Influencia de la temperatura y el pH en el desarrollo in vitro de razas de Fusarium oxysporum f. sp. ciceris. MS thesis. E.T.S.I.A.M. University of Córdoba, Spain.

10. Duthie, J. A. 1997. Models of the response of foliar parasites to the combined effects of temperature and duration of wetness. Phytopathology 87:1088-1095

11. Gupta, O., Kotasthane, S. R., and Khare, M. N. 1987. Factors influencing epidemiology of vascular wilt of chickpea. Proc. Natl. Acad. Sci. India 57:86-91.

12. Halila, M. H., and Strange, R. N. 1996. Identification of the causal agent of wilt of chickpea in Tunisia as Fusarium oxysporum f. sp. ciceri race 0. Phytopathol. Mediterr. 35:67-74.

13. Hau, B. 1988. Ein erweitertes analytisches modell für epidemien von pflanzenkrankheiten. Justus-Liebig-Universität, Habilitationsschrift, Giessen, Germany.

14. Haware, M. P., and Nene, Y. L. 1982. Races of Fusarium oxysporum f. sp. ciceri. Plant Dis. 66:809-810.

15. Haware, M. P., Jiménez-Díaz, R. M., Amin, K. S., Phillips, J. C., and Halila, H. 1990. Integrated management of wilt and root rots of chickpea. Pages 129-133 in: Proc. Second Int. Workshop Chickpea Improvement, ICRISAT, Patancheru, India.

16. ICRISAT, 1989. Annual Report 1988. ICRISAT, Patancheru, India.

17. Jalali, B. L., and Chand, H. 1992. Chickpea wilt. Pages 429-444 in: Plant Diseases of International Importance. Vol. 1. Diseases of Cereals and Pulses. U. S. Singh, A. N. Mukhopadhayay, J. Kumar, and H. S. Chaube, eds. Prentice Hall, Englewood Cliffs, NJ.

18. Jiménez-Díaz, R. M., Alcalá-Jiménez, A. R., Hervás, A., and TraperoCasas, J. L. 1993. Pathogenic variability and host resistance in the Fusarium oxysporum f. sp. ciceris/Cicer arietinum pathosystem. Pages 87-94 in: Proc. Eur. Semin. Fusarium Mycotoxins, Taxonomy, Pathogenicity and Host Resistance, 3rd. Hodowla Róslin Aklimatyzacja i Nasiennictwo. Plant Breeding and Acclimatization Institute, Radzikóv, Poland.
19. Jiménez-Díaz, R. M., Singh, K. B., Trapero-Casas, A., and Trapero-Casas, J. L. 1991. Resistance in kabuli chickpeas to Fusarium wilt. Plant Dis. 75:914-918

20. Jiménez-Díaz, R. M., Trapero-Casas, A., and Cabrera de la Colina, J. 1989. Races of Fusarium oxysporum f. sp. ciceri infecting chickpeas in southern Spain. Pages 515-520 in: Vascular Wilt Diseases of Plants. NATO ASI Series, Vol. H28. E. C. Tjamos and C. H. Beckman, eds., Springer-Verlag, Berlin.

21. Jiménez-Gasco, M. M., and Jiménez-Díaz, R. M. 2003. Development of a specific polymerase chain reaction-based assay for the identification of Fusarium oxysporum f. sp. ciceris and its pathogenic races 0, 1A, 5, and 6. Phytopathology 93:200-209.

22. Jiménez-Gasco, M. M., Milgroom, M. G., and Jiménez-Díaz, R. M. 2004. Stepwise evolution of races in Fusarium oxysporum f. sp. ciceris inferred from fingerprinting with repetitive DNA sequences. Phytopathology 94:228-235.

23. Jiménez-Gasco, M. M., Pérez-Artés, E., and Jiménez-Díaz, R. M. 2001. Identification of pathogenic races $0,1 \mathrm{~B} / \mathrm{C}, 5$, and 6 of Fusarium oxysporum f. sp. ciceris with random amplified polymorphic DNA (RAPD). Eur. J. Plant Pathol. 107:237-248.

24. Kelly, A., Alcalá-Jiménez, A. R., Bainbridge, B. W., Heale, J.B., and Pérez-Artés, E., and Jiménez-Díaz, R. M. 1994. Use of genetic fingerprinting and random amplified polymorphic DNA to characterize pathotypes of Fusarium oxysporum f. sp. ciceris infecting chickpea. Phytopathology 84:1293-1298.

25. Landa, B. B., Navas-Cortés, J. A., Hervás, A., and Jiménez-Díaz, R. M. 2001. Influence of temperature and inoculum density of Fusarium oxysporum f. sp. ciceris on suppression of Fusarium wilt of chickpea by rhizosphere bacteria. Phytopathology 91:807-816.

26. Landa, B. B., Navas-Cortés, J. A., and Jiménez-Díaz, R. M. 2004. Influence of temperature on plant-rhizobacteria interactions related to biocontrol potential for suppression of Fusarium wilt of chickpea. Plant Pathol. 53:341-352.

27. Landa, B. B., Navas-Cortés, J. A., and Jiménez-Díaz, R. M. 2004. Integrated management of Fusarium wilt of chickpea combining the use of choice of sowing date, host resistance, and biological control. Phytopathology 94:946-960.

28. Landa, B. B., Navas-Cortés, J. A., Jiménez-Gasco, M. M., Katan, J., Retig, B., and Jiménez-Díaz, R. M. 2006. Temperature response of chickpea cultivars to races of Fusarium oxysporum f. sp. ciceris, the causal agent of Fusarium wilt. Plant Dis. 90:365-374.

29. Madden, L. V., and Campbell, C. L. 1990. Nonlinear disease progress curves. Pages 181-229 in: Epidemics of Plant Diseases, Mathematical Analysis and Modeling, 2nd ed. Ecological Studies 13. J. Kranz, ed. Springer-Verlag, Berlin.

30. Navas-Cortés, J. A., Alcalá-Jiménez, A. R., Hau, B., and Jiménez-Díaz, R. M. 2000. Influence of inoculum density of races 0 and 5 of Fusarium oxysporum f. sp. ciceris on development of Fusarium wilt in chickpea cultivars. Eur. J. Plant Pathol. 106:135-146.

31. Navas-Cortés, J. A., Hau, B., and Jiménez-Díaz, R. M. 1998. Effect of sowing date, host cultivar, and race of Fusarium oxysporum f. sp. ciceris on development of Fusarium wilt of chickpea. Phytopathology 88:13381346.

32. Navas-Cortés, J. A., Hau, B., and Jiménez-Díaz, R. M. 2000. Yield loss in chickpeas in relation to development of Fusarium wilt epidemics. Phytopathology 90:1269-1278.

33. Pennypacker, S. P., Knoble, H. D., Antle, C. E., and Madden, L. V. 1980. A flexible model for studying plant disease progression. Phytopathology 70:232-235.

34. Rotem, J. 1978. Climatic and weather influences on epidemics. Pages 317-337 in: Plant Disease: An Advanced Treatise, Vol. II. J. G. Horsfall and E. B. Cowling, eds. Academic Press, New York.

35. Rubio, J., Hajj-Moussa, E., Kharrat, M., Moreno, M. T., Millán, T., and Gil, J. 2003. Two genes and linked RAPD markers involved in resistance to Fusarium oxysporum f. sp. ciceris race 0 in chickpea. Plant Breed. 122:188-191.

36. Sattar, A., Ghani Arif, A., and Mohy-ud-Din, M. 1953. Effect of soil temperature and moisture on the incidence of gram wilt. Pak. J. Sci. Res. 5:16-21.

37. Sharma, K. D., Chen, W., and Muehlbauer, F. J. 2005. Genetics of chickpea resistance to five races of Fusarium wilt and a concise set of race differentials for Fusarium oxysporum f. sp. ciceris. Plant Dis. 89:385-390.

38. Sugha, S. K., Kapoor, S. K., and Singh, B. M. 1994. Factors influencing Fusarium wilt of chickpea (Cicer arietinum L.). Indian J. Mycol. Plant Pathol. 24:97-102.

39. Trapero-Casas, A., and Jiménez-Díaz, R. M. 1985. Fungal wilt and root rot diseases of chickpea in southern Spain. Phytopathology 75:11461151. 